\title{
25 Research Soure \\ Ectopic expression of finger millet calmodulin confers drought and salinity tolerance in Arabidopsis thaliana
}

\section{Gautam Jamra}

University of Delhi - South Campus

\section{Aparna Agrawal}

G B Pant University of Agriculture and Technology: Govind Ballabh Pant University of Agriculture \&amp;

Technology

Nidhi Singh

University of Delhi - South Campus

Sibaji K. Sanyal

University of Delhi - South Campus

Anil Kumar

G B Pant University of Agriculture and Technology: Govind Ballabh Pant University of Agriculture \&amp;

Technology

Girdhar Kumar Pandey ( $\square$ gkpandey@south.du.ac.in )

University of Delhi South Campus https://orcid.org/0000-0001-9180-0924

\section{Research Article}

Keywords: Abiotic stress, calcium signalling, CaM, drought response, salinity response, overexpression

Posted Date: April 13th, 2021

DOl: https://doi.org/10.21203/rs.3.rs-383277/v1

License: (c) (1) This work is licensed under a Creative Commons Attribution 4.0 International License.

Read Full License

Version of Record: A version of this preprint was published at Plant Cell Reports on July 11th, 2021. See the published version at https://doi.org/10.1007/s00299-021-02743-z. 


\section{Abstract}

Drought and salinity are major environmental stresses which affect crop productivity and therefore are major hindrance in feeding growing population world-wide. Calcium $\left(\mathrm{Ca}^{2+}\right)$ signalling plays a crucial role during the plant's response to these stress stimuli. Calmodulin (CaM), a crucial $\mathrm{Ca}^{2+}$ sensor, is involved in transducing the signal downstream in various physiological, developmental and stress responses by modulating a plethora of target proteins. The role of CaM has been well established in the model plant Arabidopsis thaliana for regulating various developmental processes, stress signalling and ion transport. In the current study, we investigate the CaM of Eleusine coracana (common name finger millet, known especially for its drought tolerance and superior $\mathrm{Ca}^{2+}$ content). In-silico analysis showed that Eleucine calmodulin (EcCaM) has greater similarity to rice CaM as compared to Arabidopsis CaM due to the presence of highly conserved four EF-hand domains. To decipher the in planta function of EcCaM, we have adopted the gain-of-function approach by generating the 35S.:EcCaM over-expression transgenic in Arabidopsis. Overexpression of EcCaM in Arabidopsis makes the plant tolerant to polyethylene glycol (PEG) induced drought and salt stress $(\mathrm{NaCl})$ as demonstrated by post-germination based phenotypic assay, ion leakage, MDA and proline estimation, ROS detection under stressed and normal conditions. Moreover, EcCaM-overexpression leads to hypersensitivity towards exogenously applied ABA at the seed germination stage. These findings reveal that EcCaM mediates tolerance to drought and salinity stress. Also, our results indicate that EcCaM is involved in modulating ABA signalling. Summarizing our results, we report for the first time that EcCaM is involved in modulating plants response to stress and this information can be used for the generation of future-ready crops that can tolerate a wide range of abiotic stresses.

\section{Key Messages}

Overexpression of finger millet calmodulin imparts drought and salt tolerance in plants.

\section{Introduction}

Every year plants lose their growth and productivity due to various abiotic stresses, fluctuating temperature, a perturbation in soil water content, high salt salinity and others (Wang et al. 2003: Arunanondchai et al. 2018). Plants elicit a wide range of physiological and biochemical defence mechanism through the plethora of signalling pathways to adapt to these adverse environments (Pandey et al. 2016). Nearly all plant reactions to stress stimuli leads to alteration in cellular calcium $\left(\mathrm{Ca}^{2+}\right)$ concentration, which is termed as $\mathrm{Ca}^{2+}$ signatures (Pandey, 2008; Pandey and Sanyal, 2021). These $\mathrm{Ca}^{2+}$ signatures are sensed by several $\mathrm{Ca}^{2+}$ binding proteins divided into- $\mathrm{Ca}^{2+}$ sensors and $\mathrm{Ca}^{2+}$ sensor -relay proteins (Hashimoto and Kudla 2011; Ranty et al. 2016). Binding with $\mathrm{Ca}^{2+}$ ion causes conformational changes in these sensor proteins in $\mathrm{Ca}^{2+}$ dependent manner which evokes downstream signalling cascades. The majority of plant $\mathrm{Ca}^{2+}$ sensor proteins including calmodulins (CaMs), calmodulins-like 
proteins (CMLs), calcineurin B-like proteins (CBLs) and $\mathrm{Ca}^{2+}$-dependent protein kinases (CDPKs) contains acidic EF-hand $\mathrm{Ca}^{2+}$ binding motifs (DeFalco et al. 2010; Mohanta et al. 2019; Sanyal et al., 2019).

CaM is a small, ubiquitous, highly conserved protein found in almost all eukaryotic organisms, whereas CMLs are present only in higher plants (Luan et al. 2002; Tuteja and Mahajan 2007; Das et al. 2013). CaM contains four EF-hands with a high affinity to bind with four $\mathrm{Ca}^{2+}$ (Zielinski 1998) while CML protein has 1-6 EF-hands. CaM and CMLs serve as sensor relays, controlling the wide range of cellular pathways through influencing their target proteins by protein-protein interactions or change in gene expressions (Virdi et al. 2015; He et al. 2018). It is well established that various plant CaM and CML proteins were involved in physiochemical plant responses and induced by different type of stimuli and hormones (Townley and Knight 2002; Ali et al. 2003; Zeng et al. 2015; Gao et al. 2019). Glycine max GmCaM4 enhanced tolerance to high salinity conditions through interaction with Myb2 transcription factor which is the regulator of salt responsive genes in soybean (Rao et al. 2014). In Arabidopsis, binding of CaM activates calmodulin-binding transcription factor CAMTA3, which decreases salicylic acid levels and provide disease resistance through negative regulation of EDS1 (Du et al. 2009). In Arabidopsis, AtCML8 and AtCML9 alter the expression of many stress responsive-genes and knockout mutants of AtCML9 provide salt tolerance to plant through ABA-mediating signalling (Magnan et al. 2008; Park et al. 2010). Moreover, in Arabidopsis, AtCaM5 (also known as AtCML18) interacts with the AtNHX1 c-terminus in a $\mathrm{Ca}^{2+}$ and $\mathrm{pH}$-dependent manner. This interaction suggests the availability of $\mathrm{Ca}^{2+}{ }^{2+} \mathrm{pH}-$ dependent signalling encounters, which are involved in salt tolerance (Yamaguchi et al. 2005). Expression of Solanum habrochaites ShCML44 is highly upregulated under high salt, cold and drought stresses and overexpression of ShCML44 improved plant growth and tolerance to multiple abiotic stresses through regulation of many downstream genes (Munir et al. 2016). In soybean and Arabidopsis, overexpression of calmodulin-binding transcription factor GmCAMTA12 improved the growth of plants under mannitol induced drought conditions (Noman et al. 2019). In grapevine, the expression of CML21 is positively regulated by heat, cold, high salinity and drought conditions (Aleynova et al. 2020). Abiotic stress treated transcriptome data of Brassica napus revealed the alter expression of BnCaMs and BnCMLs genes (He et al. 2020). Overall, these examples of CaM and CMLs (and their interacting partner CAMTA) suggest their crucial role in $\mathrm{Ca}^{2+}$ signaling mediated modulation of plant growth and adaptation to abiotic stress.

Finger millet (Eleusine coracana $\mathrm{L}$ ) is rich in minerals and nutrients, and this cereal crop is grown in semiarid and subtropics region of the world (Fakrudin et al. 2004; Kumar et al. 2016). It is an agronomically viable crop that can grow in a wide variety of conditions, including drought, salt, waterlogging while maintaining optimal yields, as it is one of the best germplasms for abiotic stress-tolerant genes (Dida et al. 2007; Ramakrishna et al. 2018). Therefore, the adaptability capacity of finger millet to survive under different abiotic stress conditions, considered as an attractive crop for the identification of genes and pathways involved in adaptation against adverse environmental conditions (Sood et al. 2016). The United States national academies consider finger millet to be a possible "super cereal" (National Research Council, 1996), as it has 10 times more $\mathrm{Ca}^{2+}$ content than wheat, maize or brown rice (a fact that qualifies 
it as a good source for $\mathrm{Ca}^{2+}$ nutrient compared to other crops). It is also a good source of iron, zinc, fibre and essential amino acids (Vadivoo et al.1998; McDonough et al. 2000; Gupta et al. 2017).

In an earlier study, a finger millet CaM (ECCAM) was reported to be involved in high grain $\mathrm{Ca}^{2+}$ accumulation in high $\mathrm{Ca}^{2+}$ containing genotypes (Kumar et al. 2014). It was reported that EcCaM transcripts were expressed strongly in developing spikes (Singh et al. 2014) and the protein is localized more in embryo and aleurone layer of grains of high $\mathrm{Ca}^{2+}$ finger millet genotype, GP-45 (Kumar et al. 2014). It was hypothesized that higher expression and accumulation of EcCaM played a role in the drought tolerance of the GP-45 genotype (Jamra et al. 2020). So in the present study, we elucidate the in planta functioning of this finger millet calmodulin, EcCaM. We have used the Arabidopsis heterologous system for gain-of-function and tested the candidate gene for its functional role in different stress conditions.

\section{Materials And Methods}

\section{Plant and growth condition}

Finger millet GP-45 genotype was used for transcript profiling after abiotic stress treatment. For this, GP45 seeds were surface-sterilized for $5 \mathrm{~min}$. in $2 \%(\mathrm{v} / \mathrm{v})$ bleach, rinsed and soaked in autoclave milliQ (MQ) water for 1 hour and plated on $1 / 2$ MS media followed by dark incubation for 3 days. Finger millet was grown at a temperature of $27 \pm 1^{\circ} \mathrm{C}$ with a relative humidity of $70 \%$ with photoperiod $80 \mu \mathrm{mol} \mathrm{m}-2 \mathrm{~s}-1$ with a 16/8-h day/night cycle. For expression analysis, 12 days old seedlings grown on $1 / 2 \mathrm{MS}$ medium were transferred to $20 \% \mathrm{PEG}$ and $200 \mathrm{mM} \mathrm{NaCl}$ and samples were harvested with 0,3 and $6 \mathrm{hrs}$ Transgenic Arabidopsis plants, harbouring the ECCaM were grown on $1 / 2 \mathrm{MS}$ medium containing $1 \%(\mathrm{w} / \mathrm{v})$ sucrose and $0.8 \%(\mathrm{w} / \mathrm{v})$ agar in growth room maintained at $22 \pm 2 \varangle \mathrm{C}$ and $60 \%$ relative humidity under a photoperiod of $16 \mathrm{~h}$ light (light intensity $100 \mu \mathrm{mol} \mathrm{m}-2 \mathrm{~s}-1$ ) and $8 \mathrm{~h}$ darkness.

\section{In-silico characterization of EcCaM}

The nucleotide sequence of calmodulin EcCaM gene was fetched from de novo assembled transcriptome data of developing spikes of finger millet genotypes used in a previous study (Kumar et al. 2015; Singh et al. 2015). A protein blast of EcCaM protein sequence as a query sequence was performed by NCBI blast (http://blast.ncbi.nlm.nih.gov/Blast.cgi). Multiple sequence alignment of EcCaM protein sequence with their closely related protein sequences were analysed through a tool of CLC genomic server (https://digitalinsights.qiagen.com) and the phylogenetic tree was constructed through CLUSTAL W (Larkin et al. 2007).

\section{RNA isolation and Quantitative RT-PCR analysis}

Total RNA was isolated from tissue of PEG (finger millet 20\%PEG and Arabidopsis 5\% PEG) and $\mathrm{NaCl}$ (finger millet $200 \mathrm{mM}$ and Arabidopsis $125 \mathrm{mM}$ ) for varying exposure time 0,3 and $6 \mathrm{~h}$ of 12 days old seedlings by Hot-Phenol methods according to (Sanyal et al., 2017). $1 \mu \mathrm{g}$ of RNA was used to synthesis 
cDNA synthesis using Prime script@ RT reagent Kit (TaKaRa, Japan). RT-qPCR was performed using Agilent AriaMx Real-Time PCR system using Agilent SYBR qPCR Master Mix Kit according to manufactures instructions and using finger millet EcCaMRT and ECTUBULIN-RT and AtCaM-RT and AtACTIN-RT primers sets listed in Table 2. Relative expression was determined according to (Sanyal et al., 2017). For finger millet and Arabidopsis, Tubulin and Actin was used as an internal control, respectively.

\section{Generation of overexpression construct and EcCaM in Arabidopsis transgenic}

To generate EcCaM overexpressing plants, the coding region (ORF) of EcCaM was introduced in between $\mathrm{Ncol}$ and BstEl/ restriction sites of the plant transformation vector $p C A M B I A 1301$ under the control of the CaMV35S promoter. The constructs were confirmed by sequencing and then transformed into Arabidopsis wild-type plants (Col-0) by the floral dip method (Clough \& Bent, 1998). $\mathrm{T}_{0}$ seeds harvested from these plants were screened on selection media ( $1 / 2 \mathrm{MS}$ media containing $30-\mu \mathrm{g} / \mathrm{ml}$ hygromycin [Himedia, India]) to obtain $T_{1}$ plants. Subsequently, $T_{1}$ seeds were plated on MS medium (containing 30$\mu \mathrm{g} / \mathrm{ml}$ hygromycin) for the confirmation of segregation ratios and then transferred to soil till maturity to generate $T_{2}$ and $T_{3}$ generation, which were screened as homozygous transformants and used for physiological analysis.

\section{Semi-quantitative PCR for validation of overexpression lines}

Total RNA was isolated from leaf tissues of $\mathrm{Col}-\mathrm{O}$ and overexpression lines using the protocol mentioned in (Sanyal et al., 2017). The total RNA was reverse transcribed into first-strand cDNA with Prime script@ $\mathrm{RT}$ reagent Kit (TaKaRa, Japan). EcCAM Semi-quantitative PCR was performed in a thermocycler with profiling 95 for 4 mins; 95 for $30 \mathrm{sec} ; 58$ for $30 \mathrm{sec} ; 2$ for 40 sec; 72 for 7 mins at 27 cycles by using ECCaM and AtACTIN RT-PCR forward \& reverse primer listed in Table 2. RT-PCR product was visualized by electrophoresis on a $1.2 \%$ agarose gel.

\section{Post-germination based phenotypic assays under various abiotic conditions (PEG and $\mathrm{NaCl}$ )}

For the root growth assay, surface sterilized and cold-stratified of $\mathrm{Col}-\mathrm{O}$ and Arabidopsis transgenic seeds were germinated on $1 / 2 \mathrm{MS}$ agar medium for 4 days, followed by transfer to $1 / 2 \mathrm{MS}$ growth medium containing various PEG-6000 concentrations $(0,10$, or $15 \%)$ and also subjected to various $\mathrm{NaCl}$ concentration $(0,150 \mathrm{mM}$, or $175 \mathrm{mM})$. The plates were kept vertically to observed root elongation and salt-sensitive chlorosis phenotypes for daily observation.

\section{Fresh weight and total chlorophyll content}

To determined fresh weight, 5 seedlings were measured with three biological replicates. Total chlorophyll content was measured from seedlings harvested, weighted and extracted in DMSO (Barnes et al. 1992). The absorbance of supernatant was recorded at wavelength $664 \mathrm{~nm}$ and $647 \mathrm{~nm}$ and calculation was 
done by using equation with formula: [chlorophyll a + chlorophyll b] $=17.90 \times$ A647 + 8.08 x A664 (Arnon 1949).

\section{MDA, proline and ion leakage quantification}

MDA estimation was done by quantifying thiobarbituric acid reactive substances (TBARS) following the protocol by (Heath and Packer 1968). $100 \mathrm{mg}$ of samples (twelve days old seedlings treated with PEG and $\mathrm{NaCl}$ ) were homogenized in $500 \mu \mathrm{l}$ of $0.1 \%$ TCA and centrifuged at $12,000 \mathrm{rpm}$ at $4 \mathbb{} \mathrm{C}$ for 10 minutes.

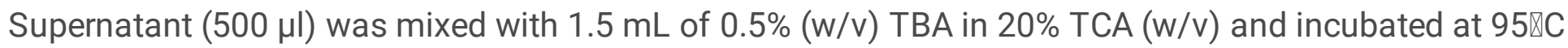
for 30 minutes. The reaction was stopped by keeping the tubes on ice followed by centrifugation for 5

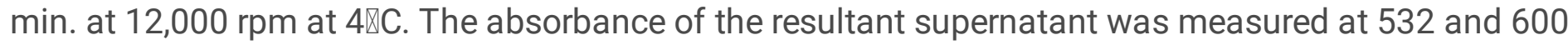
$\mathrm{nm}$. OD600 values were subtracted from MDA-TBA complexes values at $532 \mathrm{~nm}$ and MDA calculation is calculated using the Lambert-Beer law with an extinction coefficient $\varepsilon M=155 \mathrm{mM}-1 \mathrm{~cm}-1$. Values presented as $\mu$ MMDA g-1 FW.

Proline estimation was done by using (Bates et al. 1973). To quantify proline content $100 \mathrm{mg}$ (12 days old seedlings treated with PEG and $\mathrm{NaCl}$ ) were extracted in $2.0 \mathrm{ml}$ of $3 \%$ sulphosalicylic acid and the

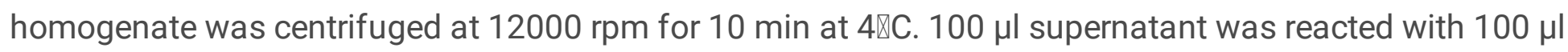
$3 \%$ sulphosalicylic acid by subsequently added $200 \mu \mathrm{l}$ glacial acetic acid and $200 \mu \mathrm{l}$ acid Ninhydrin mixtures boiling at $100 \otimes \mathrm{C}$ for 1 hour. The reaction was stopped by keeping it on ice for $30 \mathrm{~min}$ and $1.2 \mathrm{ml}$ toluene was added to the reaction mixture vortexed and centrifuges. The absorbance of the chromophore was taken at $520 \mathrm{~nm}$ using toluene as a blank. Proline concentration was determined by plotted standard curve and values expressed in $\mu \mathrm{M} \mathrm{g}-1 \mathrm{FW}$.

Electrolyte leakage was determined following the method by (Murray et al. 1989)). 12 days old seedlings were treated with PEG and $\mathrm{NaCl}$. After 12 hrs ion leakage (IL initial) was measured using a conductivity meter. The samples were then heated in a boiling water bath for $1 \mathrm{hrs}$ and complete ion leakage (IL final) of the solution was measured. Relative ion leakage was calculated by the following formula: IL initial/IL final X100.

\section{NBT and DAB staining for ROS detection}

3,3'-Diaminobenzidine (DAB) and Nitrotetrazolium blue chloride (NBT) staining was performed by using (Deepak et al. 2014). Arabidopsis thaliana seedlings of wild type Col-O and EcCaM overexpression lines were grown on $1 / 2 \mathrm{MS}$ plates for 15 days at $22^{\circ} \mathrm{C}$ under long-day conditions (16h-light/8h-dark cycle) with $200 \mu \mathrm{E}-\mathrm{m}^{-2} \mathrm{~s}^{-1}$ and $75 \%$ humidity. 15 days old seedlings were treated with a $10 \%$ PEG (drought) and $150 \mathrm{mM} \mathrm{NaCl}$ for 6 hrs. The untreated seedlings that were grown under the same conditions were served as the experimental control. Following stress treatment in assay plates, the seedlings were washed with distilled water. These seedlings were then immersed in DAB or NBT staining solution for detection of $\mathrm{H}_{2} \mathrm{O}_{2}$ or $\mathrm{O}^{2-}$, respectively. After a staining/de-staining protocol photographs were documented.

\section{Germination based phenotypic assays under ABA}


For the ABA seed germination sensitivity assay, Col- 0 and Arabidopsis transgenic seeds were germinated on $1 / 2$ MS agar medium for 7 days, followed by transfer to $1 / 2$ MS growth medium containing various ABA concentrations $(0,0.5,0.75$ or $1 \mu \mathrm{M})$ (Pandey et al., 2004). The plates were kept vertically to observed sensitive phenotype.

\section{Expression profiling of stress marker genes for drought and salinity tolerance}

For expression analysis, 12 days old seedlings of $\mathrm{Col}-\mathrm{O}$ and transgenic lines treated with $5 \%$ PEG and $125 \mathrm{mM} \mathrm{NaCl}$ and harvested at 0, 3 and $6 \mathrm{~h}$ time interval. Stress-responsive genes, SOS pathway and ABA biosynthesis genes were analysed by qRT-PCR. AtACTIN was used as an internal control. RT-qPCR was performed using Agilent AriaMx Real-Time PCR system using Agilent SYBR qPCR Master Mix Kit according to manufactures instructions and gene-specific primers listed (Table 2) in the table to analyse the expression pattern of genes responsible for drought and salt stress. Relative expression levels of genes were normalized with AtACTIN and calculated according to (Sanyal et al., 2017).

\section{Statistical Analysis}

Statistical analysis was performed by one-way ANOVA with three triplicates and each of which contain three plants using. The mean comparison was analysed by Tukey's multiple compression tests.

\section{Results}

\section{In-silico analysis of EcCaM indicates conservation of important domains in the protein and its relatedness to rice CaM}

We identified a $450 \mathrm{bp}$ long EcCaM gene from the finger millet transcriptome using the rice CaM1 gene (Genebank Accession no. XM_015766855.2) as a reference sequence (Table 1). Our particular sequence was identical to previously identified EcCaM (Kumar et al. 2014). Using In-silico analysis, we identified that the 149 amino acid residue containing EcCaM shows a high probability of having four conserved $\mathrm{Ca}^{2+}$ binding EF-hands. Fig. 1a, the multiple alignments of EcCaM with six other calmodulin protein sequences revealed that the EcCaM shared $100 \%$ sequence identity with all cereals calmodulin protein sequences, except Arabidopsis (AtCaM1), with which it showed $88 \%$ similarity. The $1^{\text {st }}-24^{\text {th }}$ amino acids of AtCaM1 differed from the EcCaM and other calmodulins, and as a result, the first EF-hand indicated gaps in our analysis. For other EF-hands, we observed sequence conservation. Some other amino acids substitutions were also found in AtCaM1 at the $75^{\text {th }}$ (Arginine to Lysine), $123^{\text {rd }}$ (Aspartate to glutamate) and $145^{\text {th }}$ (Valine to Isoleucine) positions- but all these falls outside the predicted EF-hands. The phylogenetic tree analysis of EcCaM with the following calmodulin sequences also placed the EcCaM in the same group of cereals but distinct to the AtCaM1 (Fig. 1b). The distribution of conserved motifs among CaMs also suggested that calmodulin is conserved among cereals.

Calmodulin is differentially expressed under PEG and salt treatment in Finger millet (Eleusine coracana) and Arabidopsis thaliana 
Our previous studies have established that- a) GP45 is a drought-tolerant genotype (Jamra et al. 2020) and b) CaM genes are highly expressed in GP45 (Kumar et al. 2014). So we asked if the EcCaM, we were investigating, in this study had a role in drought stress. Therefore, we performed qRT-PCR to analyse the expression profile of EcCaM under 20\% PEG induced drought stress condition we had previously used (Jamra et al. 2020) and salinity stress $(200 \mathrm{mM} \mathrm{NaCl})$ with the time frame of 3 and 6 hours after treatment. EcCaM transcript was increased within 3 hrs after exposure of the seedlings to PEG medium and reached a maximum to $6 \mathrm{hrs}$ (Fig. 2a), while exposure to $\mathrm{NaCl}$ medium EcCaM transcripts were initially elevated (within 3 hours) and then we observed a decline in the expression (6 hours) (Fig. 2a) This finding suggested that EcCaM transcripts were induced by both osmotic and salinity stress with different time intervals. One of the important questions raised here is how the distant relative of EcCaM i.e., AtCaM1 performed under similar stimuli. To address this question, we performed qRT-PCR in Arabidopsis with slight modification in the stimuli (5\% PEG and $125 \mathrm{mM} \mathrm{NaCl})$ and similar time intervals ( 3 and 6 hrs) (Fig. 2b). AtCaM1 transcript showed a similar elevation profile under PEG mediated perturbation in expression. However, under $\mathrm{NaCl}$ stress, the AtCaM1 transcript showed an enhanced expression profile even at 6 hours.

\section{Overexpression of EcCaM confers drought tolerance}

As our expression analysis indicated that EcCaM can be perturbed during drought stress, we asked if this change in expression could be linked to plants physiological response. As the transformation of finger millet is a cumbersome process, we took the heterologous expression approach to investigate our hypothesis. So we generated Arabidopsis transgenic lines with overexpression of EcCaM under the control of $35 \mathrm{~S} \mathrm{CaMV} \mathrm{constitutive} \mathrm{promoter.} \mathrm{Semi-quantitative} \mathrm{PCR/qRT-PCR} \mathrm{was} \mathrm{performed} \mathrm{to} \mathrm{determine}$ the expression levels of EcCaM, and all three transgenic lines showed expression of EcCaM transcripts compared with WT -Col-0 (Fig. 3b), and these lines were selected for further phenotypic analysis. To elucidate the role of EcCaM under drought condition post-germination based phenotypic assay was performed on $1 / 2$ MS supplemented with different PEG-6000 concentrations ( 0,10 and $15 \%)$. The increase in the PEG-6000 drastically affected the growth of WT-Col-0 seedlings. The transgenic EcCaM overexpression lines in comparison grew noticeably better than WT-Col-0 (Fig. 3a). Moreover, while compared with WT-Col-0, EcCaM overexpression lines exhibited significantly better fresh weight; longer root length and more chlorophyll levels under PEG-6000-induced drought stress (Fig. 3c and $3 \mathrm{~d}$ ). This finding reveals that all three transgenic lines exhibited more tolerance towards PEG-induced drought stress than WT-Col-0.

\section{Overexpression of EcCaM also confers salinity tolerance}

As we have observed high expression of EcCaM even under salt stress, we also investigated the phenotype of transgenic lines under salt stress. Similar to our analysis performed for PEG, we performed a post-germination based phenotype assay on different $1 / 2 \mathrm{MS}$ supplemented with various $\mathrm{NaCl}$ concentrations $(0,150,175 \mathrm{mM})$. Similar to our observed tolerance under PEG treatment, all three overexpression lines exhibited remarkably enhanced tolerance to salinity stress compared with WT-Col-0 
(Fig. 4a). We did observe some photo-bleaching (chlorosis) and stunted growth at of seedling at $175 \mathrm{mM}$ $\mathrm{NaCl}$ for all the tested lines. As expected, the EcCaM overexpression lines displayed significant fresh weight, root growth and chlorophyll content compared to WT-Col-0 under NaCl-induced salinity stress (Fig. $4 \mathrm{~b}, \mathrm{c})$. This indicates that overexpression of EcCaM can also account for enhanced salinity tolerance in transgenic lines.

\section{Overexpression of EcCaM affected membrane damage, proline accumulation and ion leakage}

To investigate the potential physiological mechanism for better drought and salinity tolerance of EcCaM overexpression lines, we estimated the MDA and proline content in the WT- Col-O and EcCaM overexpression seedlings under normal, PEG and $\mathrm{NaCl}$-mediated stress conditions. We also measured ion leakage in all the genotypes under similar condition. Under normal growth conditions, the MDA, proline and ion leakage levels of ECCaM overexpression lines and Col-O were similar. MDA levels were significantly reduced and proline was significantly higher in transgenic lines compared to WT-Col-O under both PEG and $\mathrm{NaCl}$ mediated stresses (Fig. 5a,b). We also observed that less ion leakage was exhibited by transgenic lines in comparison to WT-Col-O under both PEG and $\mathrm{NaCl}$ stress conditions (Fig. 5c). These parameters further indicate that $\mathrm{ECCaM}$ can regulate these physiological parameters to enhance the plant's defence response against abiotic stress.

\section{Reduced accumulation of reactive oxygen species in overexpression lines under drought and salinity stress conditions}

Reactive oxygen species (ROS) also plays a crucial role during plants exposure to stress (abiotic or biotic), both as a signalling molecule and molecular effector (Baxter et al., 2014). Out of many ROS species, $\mathrm{O}_{2}-$ and $\mathrm{H}_{2} \mathrm{O}_{2}$ are some of the main players that contribute to the cellular ROS pool during drought and salt stress condition. No significant difference was observed between WT-COI-O and overexpression lines under normal condition in the detection of $\mathrm{O}_{2} \cdot{ }^{-}$by NBT and $\mathrm{H}_{2} \mathrm{O}_{2}$ by DAB staining, respectively. Compared to WT-Col-0, overexpression lines showed significantly weaker NBT staining and hence it can be inferred that they have less $\mathrm{O}_{2}{ }^{-}$level under both osmotic and salinity stress (Fig. 6a). Similarly, weaker DAB staining and consequently, a lesser amount of $\mathrm{H}_{2} \mathrm{O}_{2}$ in overexpression lines as compared to WT-Col-O under osmotic and salinity stresses was observed (Fig. 6b). These results suggested that EcCaM overexpression shows a reduction in oxidative stress level and confers enhanced tolerance to drought and salinity stress.

\section{Enhanced ABA sensitivity to EcCaM transgenic lines}

Since drought perception by plants is routed through the ABA signalling pathway, we wanted to assess the response of EcCaM to ABA. So we subjected the seeds from EcCaM transgenic lines and WT-Col-O to growth on $1 / 2 \mathrm{MS}$ supplemented with different $\mathrm{ABA}$ concentration $(0,0.5,0.75$, or $1 \mu \mathrm{M})$. In absence of ABA, both ECCAaM overexpression lines and WT-Col-O had similar germination profile. However, the hypersensitivity was observed in presence of $A B A$ and this hypersensitivity was more prominent on 
increasing ABA concentration. Green cotyledon and better root morphology were apparent in WT-Col-O as compared to EcCaM overexpression seedlings on higher ABA concentration (Fig.7a,b). These results indicated that at least during germination stage, ECCaM-overexpression seeds were more sensitive to $A B A$ than WT-Col-O seeds.

\section{Overexpression of EcCaM in Arabidopsis affects transcript levels of abiotic stress-responsive, SOS pathway and ABA biosynthesis genes}

Our results indicated that the EcCaM may also modulate other important players involved in the regulation of plants response to stress stimulus. So, we examined the transcript profile of different stressrelated and $\mathrm{ABA}$ biosynthesis marker genes for drought (RD29A, RD22, COR47, KIM), salinity (majorly salt overly sensitive (SOS) pathway genes-CBL4/SOS3, CIPK24/SOS2, NHX7/SOS1 and CBL 10) and ABA (NCED3) responses (Qiu et al., 2002; Pandey et al., 2004; Kim et al., 2007). After exposure to drought stress, $R D 29 \mathrm{~A}$ transcripts reached a maximum at 3 hours further declined at 6hours. However, RD29A transcripts were expressed more in the EcCaM overexpression line as compared to WT-Col-O at 3 hours (Fig. 8a). Contrastingly, a significant difference was observed in the transcripts of COR47, RD22 and KIN between EcCaM overexpression line and WT-Col-O (Fig. 8b,c,d). For these transcripts, we observed lesser induction of transcripts in the EcCaM overexpression line compared to WT-Col-O. We also analysed the NCED transcript accumulation in WT-Col-O and ECCaM overexpression lines under drought stress. When we subjected the plants to drought stress, we observed NCED3 transcripts were significantly higher in the overexpression line as compared to WT-Col-O (Fig. 8e)

Next, we analysed the SOS pathway genes to monitor their perturbation during salt stress. In general, after salt stress, the transcripts of $C B L 4 / S O S 3$ enhanced, but we did not observe any significant difference in CBL4/SOS3 transcript levels between ECCaM overexpression line and WT-Col-0 (Fig 9a). In contrast, the transcript levels of $C B L 10$ were significantly enhanced in the ECCaM overexpression line as compared to WT-Col-O even in the control condition. Under salt stress, although the transcripts of $C B L 10$ decreased, yet we could observe EcCaM overexpression maintained comparatively higher transcripts of CBL 10 compared to WT-Col-0 (Fig. 8b). The transcripts of CIPK24/SOS2 did not significantly change in the WT-Col-O for the duration of our treatment. In the EcCaM overexpression line, overall a lower transcript

level for CIPK24/SOS2 was observed (compared to WT-Col-0), and a subtle expression perturbation on the higher side was observed after salt stress (but yet lower than WT-Col-0). (Fig. 9c). Transcripts of

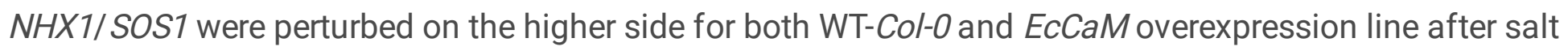
stress, but the ECCaM overexpression line maintained an overall higher level of NHX1/SOS1 after salt stress (Fig. 9dH). Lastly, we analysed the transcript profile of NCED3 in WT-Col-O and ECCaM overexpression line after salt stress. There was significant NCED3 transcript accumulation under salinity stress between the overexpression lines and WT-Col-O (Fig. 9e)

\section{Discussion}


Plants are equipped with four major gene families of $\mathrm{Ca}^{2+}$ sensor proteins (besides these four gene families more of these $\mathrm{Ca}^{2+}$ sensor are being discovered), and the CaM family of $\mathrm{Ca}^{2+}$ sensors are very well studied till date (Pandey and Sanyal, 2021). Drought and high salinity are the major environmental cues frequently experienced by plants and both impose osmotic stress on plant cells. Osmotic stress induces adverse responses at molecular and cellular levels, and a primary event as in increase in the cytosolic $\mathrm{Ca}^{2+}$ concentration, and subsequent transduction of $\mathrm{Ca}^{2+}$ signals that promote appropriate cellular responses in efforts to mitigate potential damages (Xiong and Zhu 2002). Major works on CaMs have been reported from the model plant Arabidopsis thaliana, and we only have a few studies that functionally characterizing these proteins from cereals (Magnan et al. 2008; Vadassery et al. 2012). For instance, earlier reports had indicated that CaM from Glycine max (Park et al. 2004), Oryza sativa (Saengngam et al. 2012), Vigna radita (Botella and Arteca 1994) and Hordeum vulgare (Shen et al. 2020) are involved in plants salt stress response. Our present effort is on the in-planta characterization of CaM from Eleucine coracana, also known as finger millet, a crop that holds promise for the future. To the best of our knowledge, this is the first effort to evaluate the functional aspects of the finger millet EcCaM gene for its role in drought and salinity stresses.

In the present study, we identified EcCaM in finger millet by using sequence-based search from in-house database recently developed through high a throughput transcriptome project. This particular sequence was similar to the one reported by Kumar and colleagues, who had used RACE-PCR to amplify this gene (Kumar et al. 2014). We have further through our analysis shown that important EF-hand domains are present in EcCaM and the amino acid residue match with another crop CaMs (only differing with Arabidopsis CaM1). Further as reported by Kumar and colleagues, we reconfirmed that EcCaM1 is closer to 0 . sativa CaM1 (in terms of protein sequence).

As stated earlier, the high drought tolerance of GP-45 and higher expression of EcCaM was the basis of our hypothesis to check the expression of EcCaM under drought and salt stress. Our results on EcCaM and AtCaM indicate that their expression profile is conserved even in distantly related species. As the EcCaM transcript in finger millet seedling was highly induced by drought and salinity stress, it suggested that this gene is probably involved in these stimuli. Similarly, prior findings have reported that AtCAMTA was involved in drought stress response (Pandey et al. 2013) and AtCML 9 is induced by salt, cold and ABA stress (Magnan et al. 2008). Recently one more report conferred the role of MdCaM and MdCMLs in apples under salt stress (Li et al. 2019).

The EcCaM-overexpressing seedlings displayed a more tolerant phenotype under drought and salinity stress as compared to WT-Col-O. Under PEG-mediated drought stress and NaCl-mediated salinity stress overexpression lines exhibited better fresh weight, chlorophyll content and root adaptability which suggests that overexpression of EcCaM might help in the maintenance of growth through the improvement of root development. Moreover, overexpression of EcCaM in Arabidopsis could also defend against stress-induced oxidative damage and damage to the photosynthetic system under stress. Thus our findings were similar to the previous reports that overexpression of $\mathrm{CaM} / \mathrm{CML}$ enhanced tolerance to abiotic tolerance in Arabidopsis (Larkindale and Knight 2002; Xu et al. 2011), tobacco (Li and Gong 2009; 
Zeng et al. 2015), M. truncatula (Wang et al. 2013). We further explored the physiological mechanisms by which the overexpressing lines show tolerannce to drought and salt stress than WT-Col-0. Our findings also revealed that overexpression lines accumulated more proline, less MDA content and less ion leakage than WT-Col-O under drought and salt treatment conditions. The higher accumulated proline might be allowing the overexpression lines for better effective osmoregulation, thus conferring them the observed tolerant phenotype to drought stress by minimizing the water loss and maximizing better water uptake. Proline and other solutes function in lowering cellular osmotic potential and restoring intracellular solute concentration which prevents water loss from cells (Farooq et al. 2009; Zhang et al. 2011). In agreement with prior reports that in MtCaM1 (Wang et al., 2011) overexpressing lines significant higher level of proline than that in WT-Col-O under abiotic stress, which contributed to improved tolerance to drought, salt and cold stress. Overexpression of CBL interacting protein kinases (CIPK), TaCIPK23 (Cui et al. 2018) and OsCIPKO3 and OsCIPK12 (Zhang et al. 2011) have also shown similar effects. Several effector molecules/ proteins are involved in processes like ROS scavenging and maintenance of ion homeostasis. MDA, $\mathrm{H}_{2} \mathrm{O}_{2}$ and ion leakage are also considered an indicator of oxidative damage and membrane injury (Hasegawa et al. 2000). Following prior reports, our findings also indicate that the EcCaM overexpression lines contain lesser MDA and show lesser ion leakage as reported for StCaM2 (Raina et al. 2021) and another $\mathrm{Ca}^{2+}$ sensor MsCBL4 (An et al. 2020). We posit that overexpression of EcCaM leads to elevated proline associated osmotic potential balance under stress and lesser membrane damage and ion leakage thereby resulting in the observed tolerant phenotype.

EcCaM overexpression lines also exhibited lower ROS accumulation as compared to WT-Col-O under drought and salt stress. This suggested that EcCaM overexpression enhances the antioxidant enzyme activity which enhances the ROS scavenging activity and as a result lowers the accumulation of ROS. A similar finding has been demonstrated for StCAM2, and it was reported that StCAM2 modulated the levels of antioxidant enzymes and reduced the accumulation of ROS under drought and salt stress (Raina et al.2021).

ABA plays critical roles in regulating root growth, seed germination, stomatal movement and stress responses (Bu et al. 2009; Seo et al. 2014). In our study, the detailed phenotypic analysis revealed that EcCaM overexpression lines were hypersensitive to ABA with delayed seed germination after exogenous ABA treatment. An earlier report on ectopic expression of OSMSR and CPK32 had also indicated ABAhypersensitive phenotypes during seed germination assay (Xu et al. 2011; Choi et al. 2000). We are currently unable to explain this phenotype and this requires further molecular investigation in near future.

The expression of $R D 29 A$ was strongly induced under drought conditions in EcCaM overexpressing lines while the lesser transcript of RD22, COR47 and KIN1 was observed when compared to WT-Col-O. Accordance with one of the prior report supported ours findings that overexpression of AtCPK6 does not significantly affects $R D 22$ and COR47 expression under drought stress (Xu et al 2010). For the latter three, it was expected as the transgenic lines with better stress adaptability (due to better performance of other physiological parameters) may not induce other stress pathway genes. For $R D 29 A$, we know that high drought induces its expression and posit that its upregulation in overexpression lines confer further 
tolerance towards drought stress (Yamaguchi-Shinozaki and Shinozaki 1994, Cheong et al. 2003; Pandey et al., 2004). Transcript of NCED3 was higher in ECCaM overexpressing lines as compared to WT-Col-O under drought stress. Prior reports speculated that higher NCED3 expression in overexpression of MycFOF2ox Arabidopsis plants than wild type involved in ABA catabolism and responses to drought stress (Qu et al. 2020).

SOS pathway is one of the most in-depth studied $\mathrm{Ca}^{2+}$ signalling networks under salt stress (Luan 2009; Qiu et al., 2002). CBL4/SOS3 transcript was marginally higher in WT-Col-0 (compared to transgenic lines) and CIPK2/SOS2 transcripts were not significantly perturbed, probably indicating that EcCaM did not crosstalk with the SOS pathway. However, the transcripts of AtNHX1 were enhanced significantly in EcCaM-overexpressing lines as compared to WT-Col-O under salt stress. To the best of our knowledge, there is no report indicating the crosstalk of CaM and SOS pathway (SOS are modulated majorly by the CBL-CIPK module) (Sanyal et al., 2020). However, there is one report indicating AtCML 18 was involved in salt signal transduction through interaction with AtNHX1 transporter (Yamaguchi et al. 2005). So there might be a possibility that overexpression of EcCaM target SOS1 directly/or indirectly as per our experiments showing enhanced expression of SOS1. Interestingly, CBL 10 expression was higher in EcCaM overexpression lines. CBL10 and SOS2/CIPK24 in Arabidopsis can also regulate vacuolar salt sequestration (Sanyal et al., 2015). We propose that the EcCaM might regulate some sodium transporters such as SOS1). ECCAM-overexpression harbours higher NCED3 accumulation as compared to WT-Col-O when exposed to salinity stress. For salt stress, EcCaM works in ABA dependent pathway to provide tolerance to the plants. EcCaM overexpression might be an important regulatory player for the regulation of $A B A$ biosynthesis and signalling under drought and salt stress, however, our phenotype in ABA indicates that this simple explanation will not suffice to fully explain the phenomenon and requires further investigation.

\section{Conclusion}

Our findings have revealed that EcCaM play important role in drought and salinity stresses responses. Furthermore, we have shown EcCaM transgenic lines have lesser ROS accumulation, better metabolite balance and stress-responsive and ABA biosynthesis gene profile under drought and salt stresses. In nutshell, EcCaM, a novel calmodulin protein identified from finger millet holds the potential for its use in the biotechnological improvement of crops for developing stress tolerance trait. Exploring the detailed protein function of EcCaM and further research to clarify the molecular mechanism that resulted in the stress-tolerant phenotype will improve our understanding of the $\mathrm{Ca}^{2+}$ signalling component's regulatory mechanism in crop plants.

\section{Declarations}

\section{Author contribution statement}


GKP and AK conceived and planned the research. GJ, AA and NS conducted experiments. GJ, AA, NS, SKS, AK and GKP analysed the data. GJ and GKP wrote and revised the manuscript.

\section{Acknowledgment}

We acknowledge Department of Plant Molecular Biology, University of Delhi South Campus and G. B. Pant Agriculture and Technology University for providing facilities to conduct this research work. This study was supported by Department of Biotechnology (Project code 7069) to AK. Research work in GKP's lab is supported by Delhi University (loE/FRP grant), Board of Research in Nuclear Sciences (BRNS), Department of Biotechnology (DBT), Science and Engineering Research Board (SERB), Council for Scientific and Industrial Research (CSIR), India. GJ, AA and SKS acknowledges DBT fellowship and a NS is thankful to UGC, India for D. S. Kothari postdoctoral fellowship.

\section{Conflict of interest}

Authors declares no conflict of interest

\section{References}

Aleynova OA, Kiselev KV, Ogneva ZV, Dubrovina AS (2020) The Grapevine Calmodulin-Like Protein Gene CML21 Is Regulated by Alternative Splicing and Involved in Abiotic Stress Response. Int J Mol Sci $21: 7939$

Ali GS, Reddy VS, Lindgren PB et al (2003) Differential expression of genes encoding calmodulinbindingproteins in response to bacterial pathogens and inducers of defense responses. Plant Mol Biol 51:803-815

An Y, Yang XX, Zhang L et al (2020) Alfalfa MsCBL4 enhances calcium metabolism but not sodium transport in transgenic tobacco under salt and saline-alkali stress. Plant Cell Rep 39:997-1011

Arnon DI (1949) Copper enzymes in isolated chloroplasts- Polyphenoloxidase in Beta vulgaris. Plant Physiol 24:1-15

Barnes JD, Balaguer L, Manrique E et al (1992) A reappraisal of the use of DMSO for the extraction and determination of chlorophylls $a$ and $b$ in lichens and higher plants. Environ Exp Bot 32:85-100

Bates LS, Waldren RP, Teare ID (1973) Rapid determination of free proline for water-stress studies. Plant Soil 39:205-207

Baxter A, Mittler R, Suzuki N (2014) ROS as key players in plant stress signalling. J Exp Bot 65: 1229-1240 Botella JR, Arteca RN (1994) Differential expression of two calmodulin genes in response to physical and chemical stimuli. Plant Mol Biol 24:757-766 
Bu Q, Li H, Zhao Q et al (2009) The Arabidopsis RING finger E3 ligase RHA2a is a novel positive regulator of abscisic acid signaling during seed germination and early seedling development. Plant Physiol 150:463-481

Cheong YH, Kim KN, Pandey GK (2003) CBL1, a calcium sensor that differentially regulates salt, drought, and cold responses in Arabidopsis. Plant Cell 15:1833-45

Choi $\mathrm{H}$, Hong J, Ha J et al (2000) ABFs, a family of ABA-responsive element binding factors. J Biol Chem 275:1723-1730

Clough SJ, Bent AF (1998) Floral dip: a simplified method for Agrobacterium-mediated transformation of Arabidopsis thaliana. Plant J 16:735-43

Cui XY, Du YT, Fu JD et al (2018) Wheat CBL-interacting protein kinase 23 positively regulates drought stress and ABA responses. BMC Plant Biol 18:93. https://doi.org/10.1186/s12870-018-1306-5

DeFalco TA, Bender KW, Snedden WA (2010) Breaking the code: $\mathrm{Ca}^{2+}$ sensors in plant signalling. Biochem J 425:27-40

Dida MM. Ramakrishnan SS, Bennetzen JL et al (2007) The genetic map of finger millet, Eleusine coracana. Theor Appl Genet 114:321-332

Du LQ, Ali GS, Simons KA et al (2009) Ca2+/calmodulin regulates salicylic-acid-mediated plant immunity. Nat 457:1154-U1116

Fakrudin B, Kulkani RS, Shashidhar HE, Hittalmani S (2004) Genetic diversity assessment of finger millet, Eleusine coracana (Gaertn), germplasm through RAPD analysis. Biodivers Int Newsl 138:50-54

Farooq M, Wahid A, Lee DJ et al (2009) Advances in drought resistance of Rice. Crit Rev Plant Sci 28:199-217

Gao QY, Xiong TT, Li XP et al (2019) Calcium and calcium sensors in fruit development and ripening. Sci Hortic 253:412-421.

Gupta SM, Arora S, Mirza N et al (2017) Finger millet: A "certain" crop for an "uncertain" future and a solution to food insecurity and hidden hunger under stressful environments. Front Plant Sci 8:643 .

Hasegawa PM, Bressan RA, Zhu JK, Bohnert HJ (2000) Plant cellular and molecular responses to high salinity. Annu Rev Plant Physiol Plant Mol Biol 51:463-499

Hashimoto K, Kudla J (2011) Calcium decoding mecahnism in plants. Biochimie 93:2054-2059

He M, He CQ He, Ding NZ (2018) Abiotic stresses: General defenses of land plants and chances for engineering multistress tolerance. Front Plant Sci 9:1771 
He X, Liu W, Li W et al (2020) Genome-wide identification and expression analysis of CaM/CML genes in Brassica napus under abiotic stress. J Plant Physiol 255:153251

Heath RL, Packer L (1968) Photoperoxidation in isolated chloroplasts. I. Kinetics and stoichiometry of fatty acid peroxidation. Arch Biochem Biophys 125:189-198.https://doi.org/10.1016/S01689452(02)00037-7.

Jamra G, Shah P, Agarwal A et al (2020) Elucidating the physio-morphological and biochemical responses towards PEG-induced drought stress in finger millet genotypes. Int J Curr Microbiol App Sci 9:1672-1687.

Kim BG, Waadt R, Cheong YH et al (2007) The calcium sensor CBL10 mediates salt tolerance by regulating ion homeostasis in Arabidopsis. Plant J 52: 473-484

Kumar A, Gaur VS, Goel A, Gupta AK (2015) De novo assembly and characterization of developing spikes transcriptome of finger millet (Eleusine coracana): A minor crop having nutraceutical properties. PlantMol Biol Rep 33:905-922.

Kumar A, Metwal M, Kaur S et al (2016) Nutraceutical value of finger millet [Eleusine coracana (L.) Gaertn.], and their improvement using omics approaches. Front Plant Sci 7:934.

Kumar A, Mirza N, Charan T et al (2014a) Isolation, characterization and immunolocalization of a seed dominant CaM from Finger Millet (Eleusine coracana L. Gartn.) for studying its functional role in differential accumulation of calcium in developing grains. Appl Biochem Biotechnol 172: 2955-2973.

Kumar D, Yusuf MA, Singh P et al (2014b) Histochemical detection of superoxide and $\mathrm{H}_{2} \mathrm{O}_{2}$ accumulation in Brassica juncea seedlings. Bio-protocol 4:e1108. DOI: 10.21769/BioProtoc.1108.

Larkin MA, Blackshields G, Brown NP et al (2007) Clustal W and Clustal X version 2.0. Bioinformatics 23:2947-2948.

Larkindale J, Knight MR (2002) Protection against heat stress-induced oxidative damage in Arabidopsis involves calcium, abscisic acid, ethylene, and salicylic acid. Plant Physiol 128:682-695.

Li C, Meng D, Zhang J, Cheng L (2019) Genome-wide identification and expression analysis of calmodulin and calmodulin-like genes in apple (Malusx domestica). Plant Physiol Biochem 139:600-612.

Li ZG, Gong M (2009) Involvement of calcium and calmodulin in mechanical stimulation-induced heat tolerance in tobacco (Nicotiana tabacum L.) suspension cultured cells. Plant Physiol Commun 45:363365 .

Luan S (2009) The CBL-CIPK network in plant calcium signaling. Trends Plant Sci 14:37-42. 
Magnan F, Ranty B, Charpenteau M et al (2008) Mutations in AtCML9, a calmodulin-like protein from Arabidopsis thaliana, alter plant responses to abiotic stress and abscisic acid. Plant J 56:575-589.

McDonough CM, Rooney LW, Saldivar S (2000) "The Millets," in Handbook of Cereal Science and Technology, eds K. Kulp and J. G. Ponte Jr (New York, NY: Marcel Dekker Inc.), 177-195.

Mohanta TK, Yadav D, Khan AL et al (2019) Molecular players of EF-hand containing calcium signaling event in plants. Int J Mol Sci 20:1476

Murray MB, Cape JN, Fowler D (1989) Quantification of frost damage in plant tissues by rates of electrolyte leakage. New Phytol 113:307-311.

National Research Council (1996). Lost Crops of Africa: Grains, Vol. I. Washington, DC: The National Academies Press.

Noman M, Jameel A, Qiang WD et al (2019) Overexpression of GmCAMTA12 enhanced drought tolerance in Arabidopsis and soybean. Int J Mol Sci 20:4849.

Pandey GK (2008) Emergence of a novel calcium signaling pathway in plants: CBL-CIPK signaling network. Physiol Mol Biol Plants 14: 51-68

Pandey GK, Cheong YH, Kim KN et al (2004) The calcium sensor calcineurin B-like 9 modulates abscisic acid sensitivity and biosynthesis in Arabidopsis. Plant Cell 16: 1912-1924

Pandey GK, Sanyal SK (2021) Functional Dissection of Calcium Homeostasis and Transport Machinery in Plants, Ed 1. Springer International Publishing

Pandey N, Ranjan A, Pant P et al (2013) CAMTA 1 regulates drought responses in Arabidopsis thaliana. BMC Genomics 14:216.

Park HC, Kim ML, Kang YH et al (2004) Pathogen- and NaCl-induced expression of the SCaM-4 promoter is mediated in part by a GT-1 box that interacts with a GT-1-like transcription factor. Plant Physiol 135:2150-2161.

Park HC, Park CY, Koo SC et al (2010) AtCML8, a calmodulin-like protein, differentially activating CaMdependent enzymes in Arabidopsis thaliana. Plant Cell Rep 29:1297-1304.

Perochon A, Aldon D, Galaud JP, Ranty B (2011) Calmodulin and calmodulin-like proteins in plant calcium signaling. Biochimie 93:2048-2053.

Qiu QS, Guo Y, Dietrich MA et al (2002) Regulation of SOS1, a plasma membrane $\mathrm{Na}^{+} / \mathrm{H}^{+}$exchanger in Arabidopsis thaliana, by SOS2 and SOS3. Proc Natl Acad Sci U.S.A 99: 8436-8441 
Qu L, Sun M, Li et al (2020) The Arabidopsis F-box protein FOF2 regulates ABA-mediated seed germination and drought tolerance. Plant Sci 301:110643

Raina M, Kumar A, Yadav N et al (2021) StCaM2, a calcium binding protein, alleviates negative effects of salinity and drought stress in tobacco. Plant Mol Biol

Ramakrishna C, Singh S, Raghavendrarao S et al (2018) The membrane tethered transcription factor EcbZIP17 from finger millet promotes plant growth and enhances tolerance to abiotic stresses. Sci Rep 8:2148.

Ranty B, Aldon D, Cotelle V et al (2016) Calcium sensors as key hubs in plant responses to biotic and abiotic stresses. Front Plant sci 7:327.

Rao SS, El-Habbak MH, Havens WM et al (2014) Overexpression of GmCaM4 in soybean enhances resistance to pathogens andtolerance to salt stress. Mol Plant Pathol 15:145-160.

Saeng-ngam S, Takpirom W, Buaboocha T et al (2012) The role of the OsCam1-1 salt stress sensor in ABA accumulation and salt tolerance in rice. J Plant Biol 55:198-208

Sanyal SK, Kanwar P, Samtani H, et al (2017) Alternative Splicing of CIPK3 Results in Distinct Target Selection to Propagate ABA Signaling in Arabidopsis. Front Plant Sci 8: 1924

Sanyal SK, Mahiwal S, Nambiar DM, Pandey GK (2020) CBL-CIPK module-mediated phosphoregulation: facts and hypothesis. Biochem J 477: 853-871

Sanyal SK, Mahiwal S, Pandey GK (2019) Calcium Signaling: A Communication Network that Regulates Cellular Processes. In S Sopory, ed, Sensory Biology of Plants. Springer, Singapore, pp 279-309

Sanyal SK, Pandey A, Pandey GK (2015) The CBL-CIPK signaling module in plants: a mechanistic perspective. Physiol Plant 155: 89-108

Seo KI, Lee JH, Nezames CD et al (2014) ABD1 is an Arabidopsis DCAF substrate receptor for CUL4DDB1-based E3 ligases that acts as a negative regulator of abscisic acid signaling. Plant Cell 26:695711.

Shen Q, Fu L, Su T et al (2020) Calmodulin HvCaM1 negatively regulates salt tolerance via modulation of HvHKT1s and HvCAMTA4. Plant Physiol 183:1650-1662

Shi B, Ni L, Zhang A et al (2012) OsDMI3 is a novel component of abscisic acid signaling in the induction of antioxidant defense in leaves of rice. Mol Plant 5:1359-1374. 10.1093/mp/sss068

Shi H, Quintero FJ, Pardo JM, Zhu JK. (2002) The putative plasma membrane $\mathrm{Na}^{(+)} / \mathrm{H}^{(+)}$antiporter SOS1 controls long-distance $\mathrm{Na}(+)$ transport in plants. Plant Cell 14:465-477. 
Singh UM, Metwal M, Singh M et al (2015) Identification and characterization of calcium transporter gene family in finger millet in relation to grain calcium content. Gene 566:37-46.

Sood S, Kumar A, Babu BK et al (2016) Gene discovery and advances in finger millet [Eleusine coracana (L.) Gaertn.] genomics an important nutri-cereal of future. Front Plant Sci 7:1-17.

Sun $T$, Wang $Y$, Wang M et al (2015) Identification and comprehensive analyses of the CBL and CIPK gene families in wheat (Triticum aestivum L.). BMC Plant Biol 15:1-17

Townley HE, Knight MR (2002) Calmodulin as a potential negative regulator of Arabidopsis COR gene expression. Plant Physiol128:1169-1172.

Tuteja N, Mahajan S (2007) Calcium signaling network in plants: an overview. Plant Signal Behav 2:7985.

Vadassery J, Reichelt M, Hause B et al (2012) CML42-mediated calcium signaling coordinates responses to Spodoptera herbivory and abiotic stresses in Arabidopsis. Plant Physiol 159:1159-1175.

Vadivoo AS, Joseph R, Ganesan NM (1998) Genetic variability and diversity for protein and calcium contents in finger millet (Eleusine coracana $(\mathrm{L})$ Gaertn) in relation to grain colour. Plant Foods Hum Nutr 52:353-364.

Virdi AS, Singh S, Singh P (2015) Abiotic stress responses in plants: Roles of calmodulin-regulated proteins. Front Plant Sci 6:600.

Wang TZ, Zhang JL, Tian QY et al (2013) A Medicago truncatula EF-Hand family gene, MtCaMP1, is involved in drought and salt stress tolerance. PLoS One 8:58952

Xiong L, Zhu JK (2002) Molecular and genetic aspects of plant responses to osmotic stress. Plant Cell Environ 25:31-139. 10.1046/j.1365-3040.2002.00782.x

Xu G, Rocha PSCF, Wang M et al (2011) A novel rice calmodulin-like gene, OsMSR2, enhances drought and salt tolerance and increases ABA sensitivity in Arabidopsis. Planta 234:47-59.

Xu J, Tian YS, Peng RH et al (2010) AtCPK6, a functionally redundant and positive regulator involved in salt/drought stress tolerance in Arabidopsis. Planta 231:1251-1260

Yamaguchi T, Aharon GS, Sottosanto JB, Blumwald E (2005) Vacuolar $\mathrm{Na}+/ \mathrm{H}+$ antiporter cation selectivity is regulated by calmodulin from within the vacuole in a $\mathrm{Ca} 2+-$ and $\mathrm{pH}$-dependent manner. Proc Natl Acad Sci U.S.A. 102:16107-16112. 10.1073/pnas.0504437102

Yamaguchi-Shinozaki K, Shinozaki K (1994) A novel cis-acting element in an Arabidopsis gene is involved in responsiveness to drought, low-temperature, or high-salt stress. Plant Cell 6:251-64. 
Yokoi S, Quintero FJ, Cubero B et al (2002) Differential expression and function of Arabidopsis thaliana $\mathrm{NHX} \mathrm{Na+/H+} \mathrm{antiporters} \mathrm{in} \mathrm{the} \mathrm{salt} \mathrm{stress} \mathrm{response.} \mathrm{Plant} \mathrm{J} \mathrm{30:} \mathrm{529-539.}$

Zeng H, Xu L, Singh A et al (2015) Involvement of calmodulin and calmodulin-like proteins in plant responses to abiotic stresses. Front Plant Sci6:600

Zhang HY, Mao XG, Jing RL et al (2011) Characterization of a common wheat (Triticum aestivum L.) TaSnRK2.7 gene involved in abiotic stress responses. J Exp Bot 62:975-88

Zielinski R E (1998) Calmodulin and calmodulin-binding proteins in plants. Annu Rev Plant Physiol Plant Mol Biol 49:697-725

\section{Tables}

Table 1: Calmodulin (CaM) sequences from different plant species used in multiple sequence alignment study)

\begin{tabular}{|lll|}
\hline Gene Name & Species & Genbank accession numbers \\
\hline EcCAM : calmodulin & Eleucine coracana & ACX56274.1 \\
\hline OsCAM1 : calmodulin-1 & Oryza sativa Japonica & XP_015622341.1 \\
\hline OsCAM : calmodulin & Oryza sativa Japonica & XP_015631102.1 \\
\hline ZmCAM : calmodulin1 & Zea mays & NP_001281081.1 \\
\hline ScCAM : calmodulin & Setaria italica & XP_004984568.1 \\
SbCAM : calmodulin & Sorghum bicolor & XP_002467948.1 \\
\hline AtCAM1 : calmodulin1 & Arabidopsis thaliana & NP_001330399.1 \\
\hline
\end{tabular}

Table 2: Primers used in experiments 


\begin{tabular}{|c|c|c|c|}
\hline S.No. & Genes & Forward $5^{\prime}-3^{\prime}$ & Reverse $5^{\prime}-3^{\prime}$ \\
\hline 1 & ECCAM -RT & ATGATCAATGAGGTTGATGCTG & TCCTCATCGGTTAGCTTCTCTC \\
\hline 2 & $\begin{array}{l}\text { ECTUBULIN- } \\
R T\end{array}$ & TAC TTT GTC GAG TGG ATC CC & GCG GAA CAT CTC CTG GAT G \\
\hline 3. & ECCAM-FL & CATGCCATGGATGGCGGACCAGCTCACC & $\begin{array}{l}\text { GGTNACC } \\
\text { TCACTTGGCCATCATCACC }\end{array}$ \\
\hline 4. & AtCAM & GGTGATGATGATGATGATGAT & CACACAAAAGTCACAAACCAG \\
\hline 5. & AtACTIN & CTTGCACCAAGCAGCATGAA & CCACCGATCCAGACACTGTACTT \\
\hline 6. & AtRD29A-RT & GTG CCG ACG GGA TTT GAC & CTG ATG CCT CAC CGT ATC CA \\
\hline 7. & AtCOR47-RT & CCACGCCGTTGGTTGTAAC & CTCCGGATGTTCCACTGGAA \\
\hline 8. & AtKIN1-RT & GGC AGC GGG AGG TGT TAA C & $\begin{array}{l}\text { TGA CCC GAA TCG CTA CTT } \\
\text { GTT }\end{array}$ \\
\hline 9. & AtRD22-RT & CATGAGTCTCCGGGAGGAAGTG & CGGCTGGGGTAAAGAAGTTGTC \\
\hline 10. & AtCBL4-RT & GCTTTCGTGCAAGCAGACCG & GATATGGCAAAGTCATGTTC \\
\hline 11. & AtCBL 10-RT & AGATCAAGCTCTCTCACTGT & CAATCGAAGCATTGTCCGAC \\
\hline 12. & AtCIPK24-RT & ATAAAAGTTTGTAAAGAATG & GCAAACTTAACCTTAGCAAA \\
\hline 13. & AtNHX-RT & GGA GAC AAT TTG ATG ACT C & СTT ACT AAG ATC AGG AGG G \\
\hline 14. & AtNCED3-RT & TAA CGC CGT TAG CTT AGA GG & ACC TGC TTC GCC AAA TCA TC \\
\hline
\end{tabular}

\section{Figures}

(a)

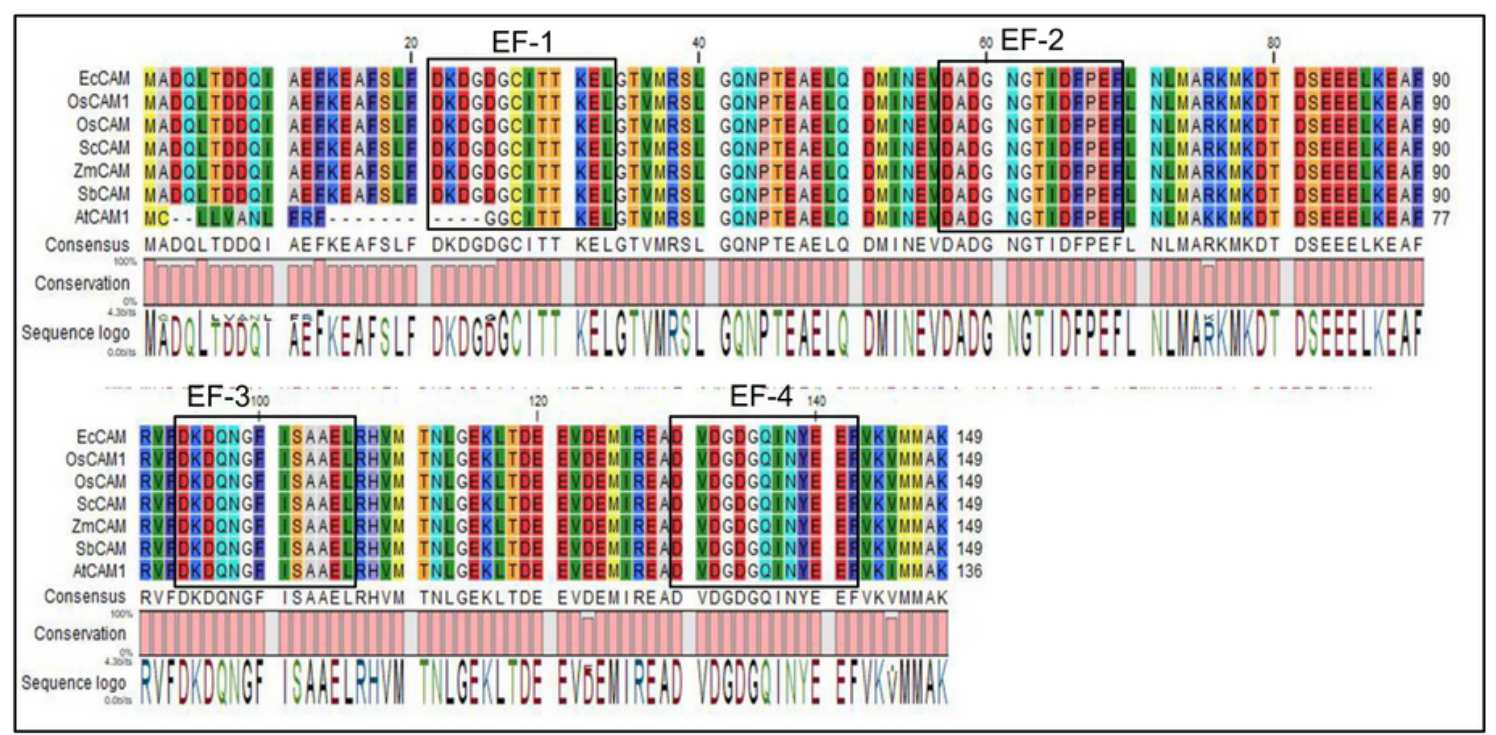

(b)

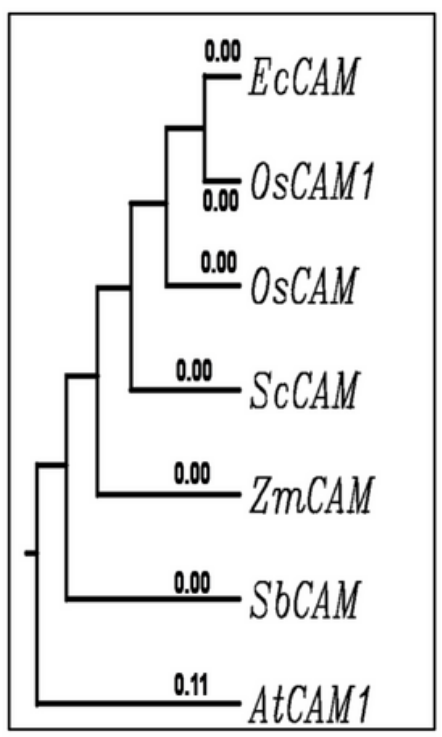


Figure 1

Sequence alignment, phylogenetic tree and motif analysis of EcCAM protein sequence A) Multiple sequence alignment of EcCaM protein with related plant $\mathrm{CaM}$ indicating conservation among sequences done by CLC genomic sequence viewer. Black boxes indicating presence of characteristic 4 EF-hands in all proteins. B) Phylogenetic tree based on the CaM protein sequences created by Clustal W.

(a)

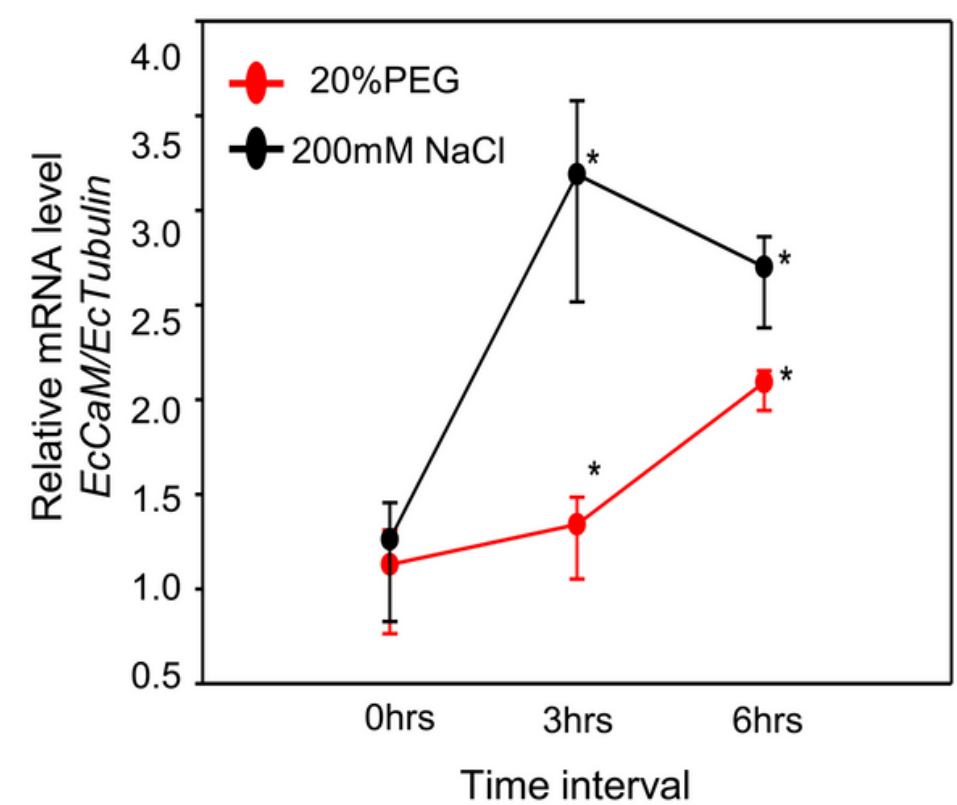

(b)

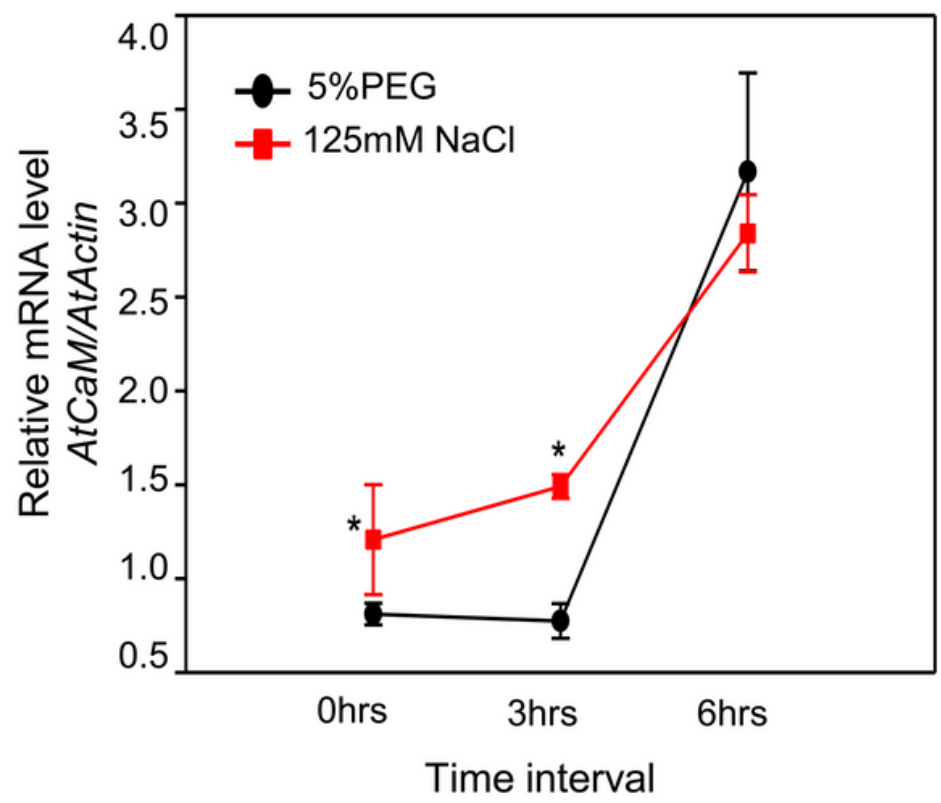

\section{Figure 2}

Calmodulin expression profiling in Finger millet (Eleucine coracana) and Arabidopsis thaliana under abiotic stresses. a) EcCAM expression pattern under 20\% PEG stress and 200mM NaCl exposure time 0-6 hrs using EcTUBULIN loading control. b) AtCAM expression pattern under $5 \%$ PEG and $125 \mathrm{mM} \mathrm{NaCl}$ exposure time 0-6 hrs using AtACTIN loading control. The data were presented as the mean \pm SD of three independent experiments. Asterisks above each column indicate statistical difference to $0 \mathrm{hrs}$ and more exposure treatments $\left({ }^{\star} \mathrm{P}<0.05 ; * \star \mathrm{P}<0.01\right)$. 
(a)

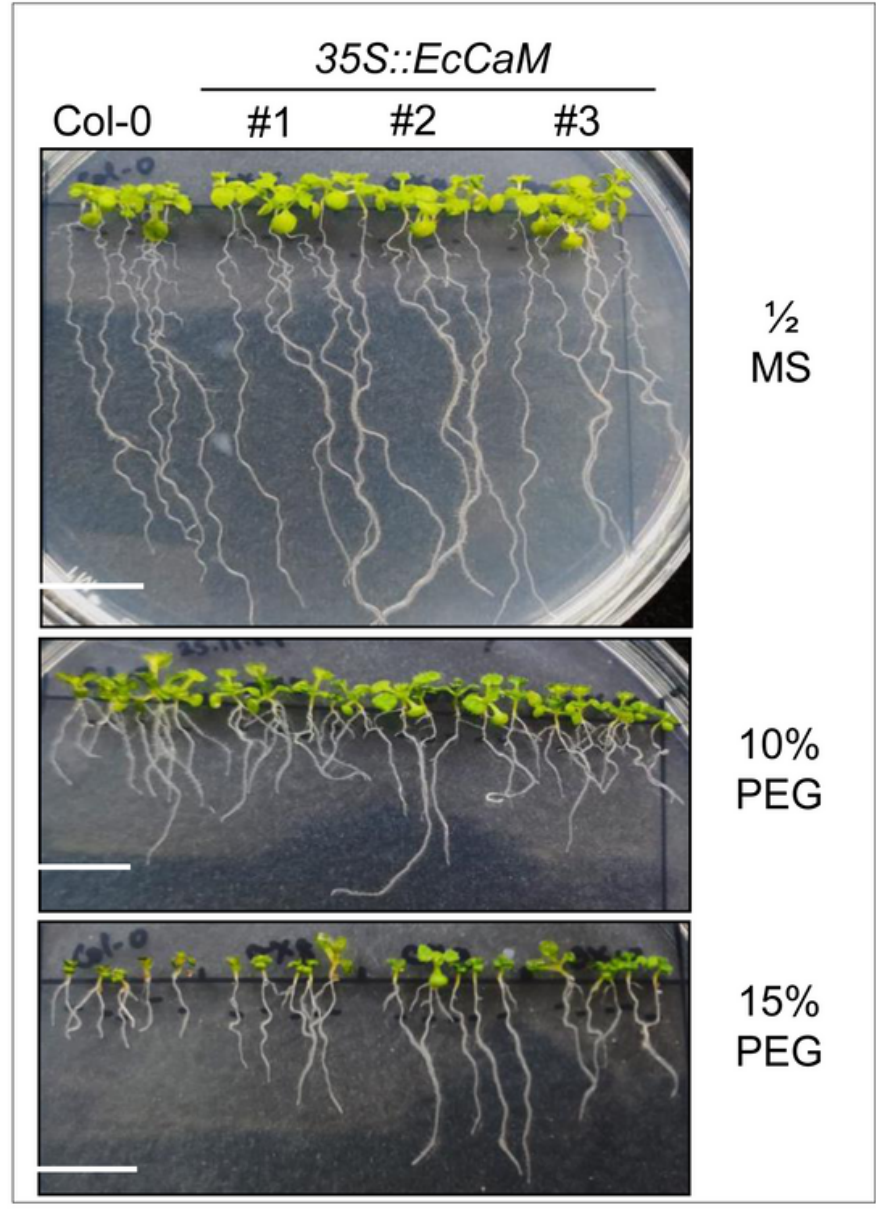

(b)

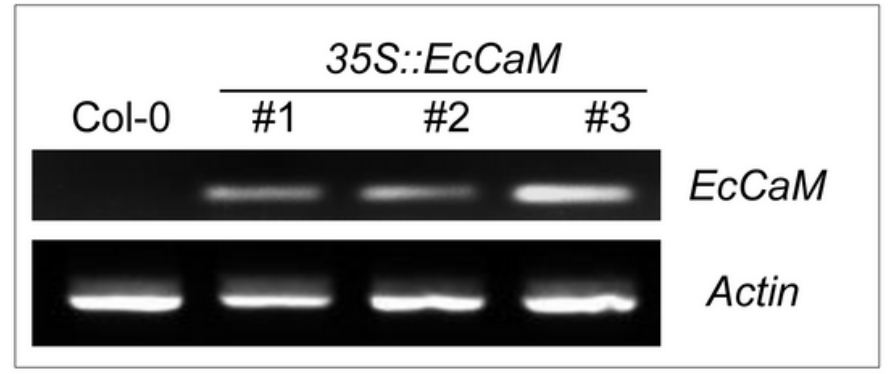

(c)

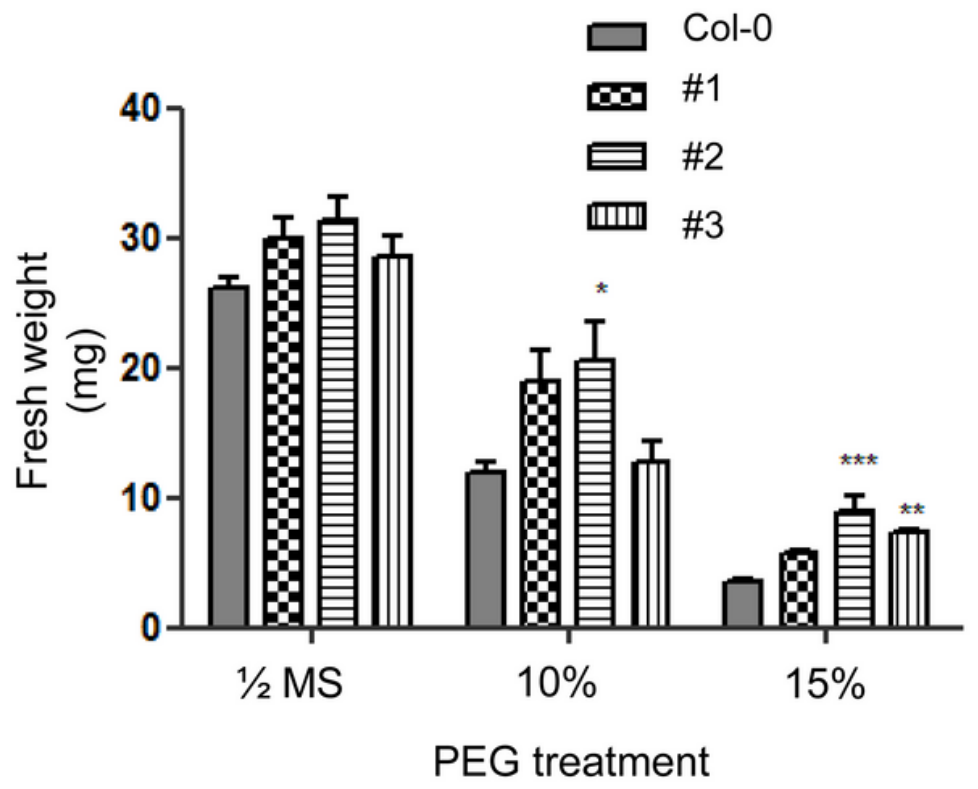

(d)

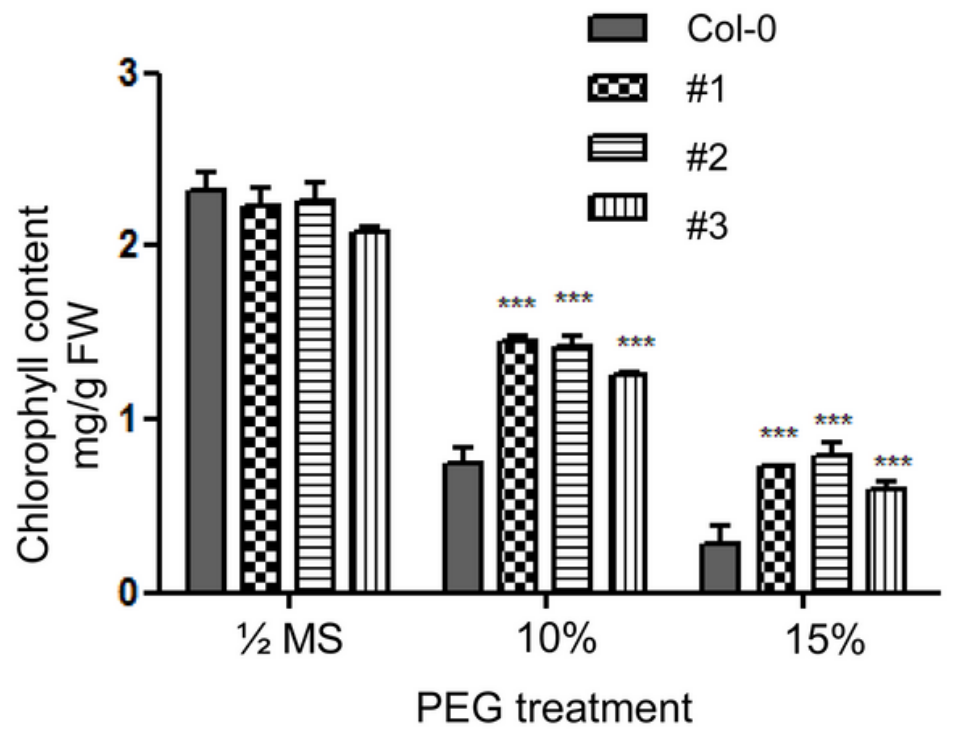

Figure 3

Overexpression of EcCAM in Arabidopsis enhanced drought tolerance. A) 4 days old seedling gown on $1 / 2$ MS transferred to $1 \frac{1}{2}$ MS containing various concentration of PEG (0, 10 and $\left.15 \%\right)$. B) RT-PCR analysis of EcCAM gene expression from EcCAM-overexpression and Col-0 and actin expression was used as loading control. C) Quantification of fresh weight. A) Quantification of chlorophyll content. The data were presented as the mean $\pm \mathrm{SD}$ of three independent experiments. Asterisks above each column indicate statistical difference between Col-0 and overexpression lines ( ${ }^{\star} P<0.05$; ${ }^{\star \star} P<0.01$; ${ }^{* \star *} P<0.001$ ) by oneway ANOVA. 
(a)

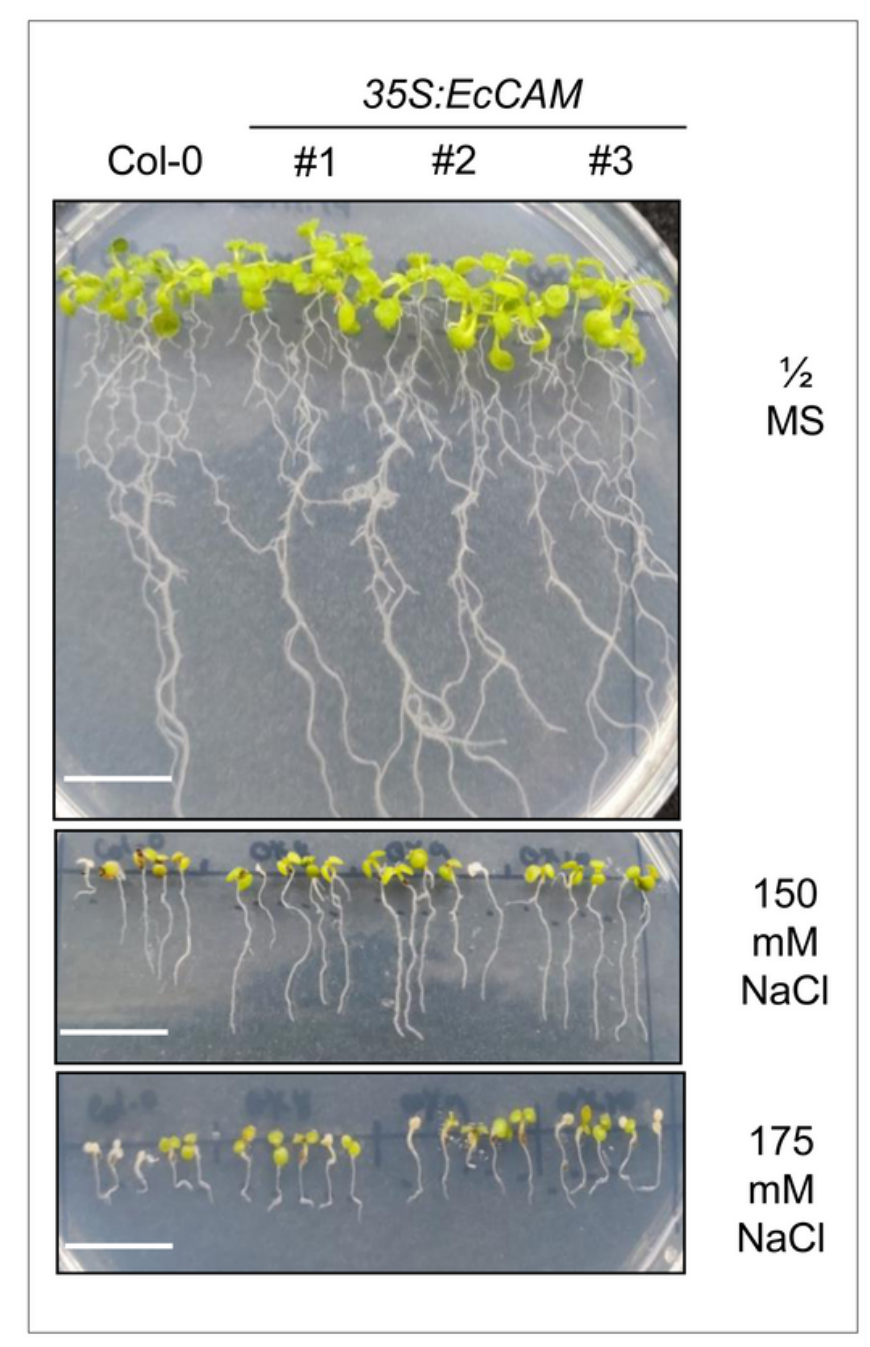

(b)

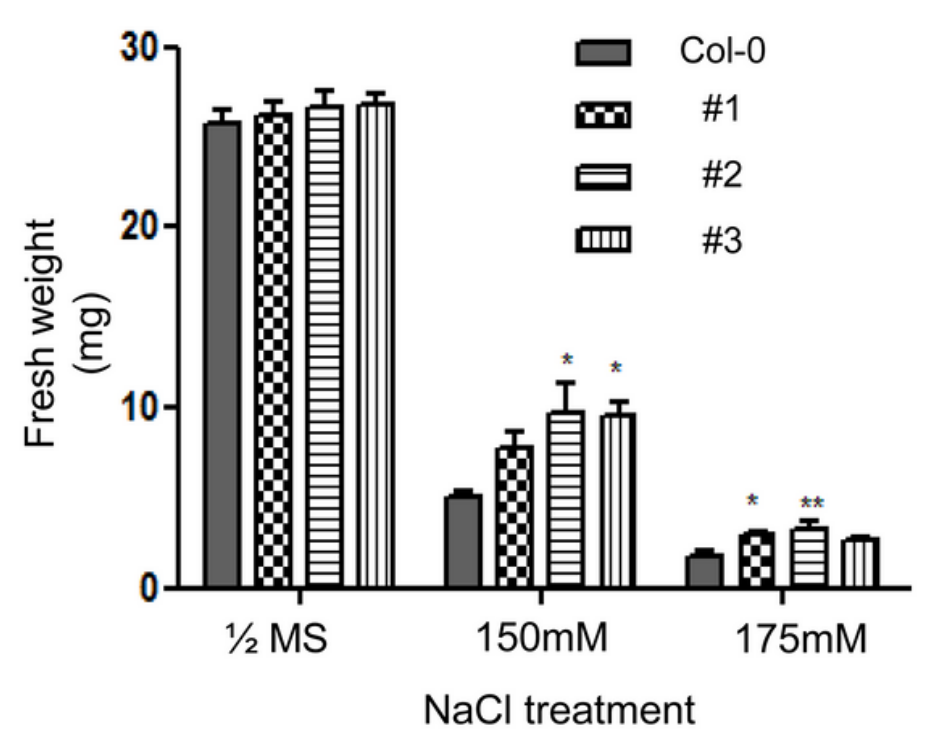

(c)

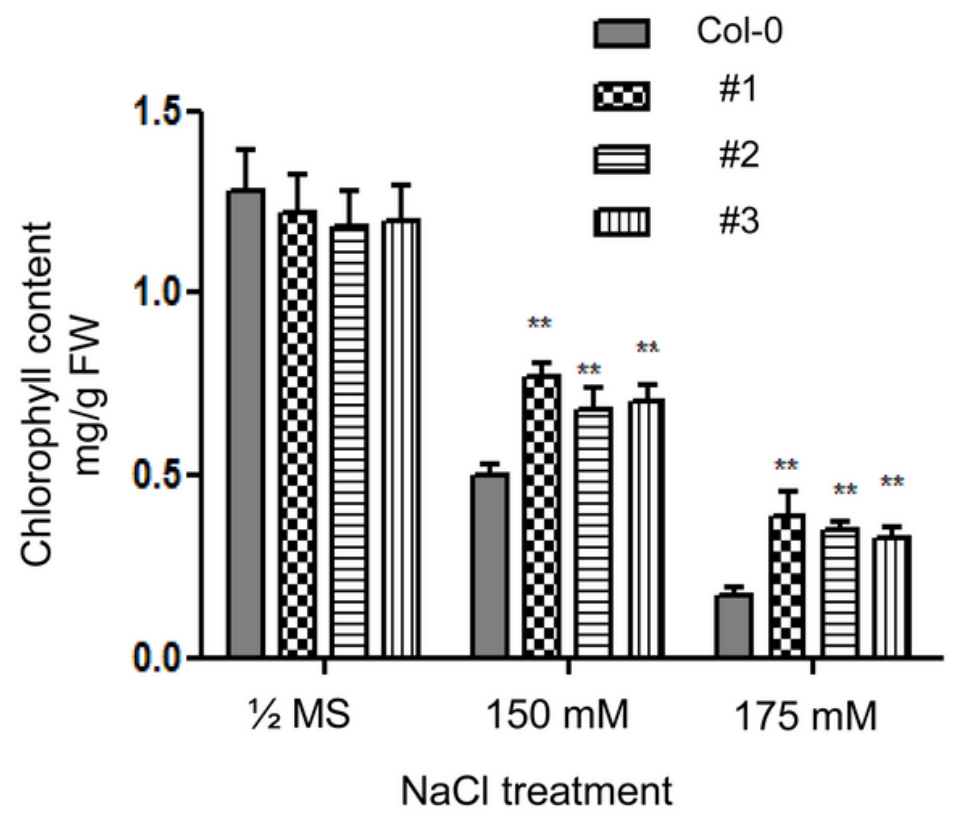

\section{Figure 4}

Overexpression of EcCAM in Arabidopsis enhanced salt tolerance. A) 4 days old seedling gown on $1 / 2$ MS transferred to $1 / 2 \mathrm{MS}$ containing various concentration of $\mathrm{NaCl}(0,150$ and $175 \mathrm{mM})$. B) RT-PCR analysis of EcCAM gene expression from EcCAM-overexpression and Col-0 and ACTIN expression was used as loading control. C) Quantification of fresh weight. B) Quantification of chlorophyll content. The data were presented as the mean $\pm \mathrm{SD}$ of three independent experiments. Asterisks above each column indicate statistical difference between WT-Col-0 and overexpression lines ( $\left.{ }^{*} P<0.05 ; * * P<0.01 ; * \star * P<0.001\right)$ by one-way ANOVA. 
(a)

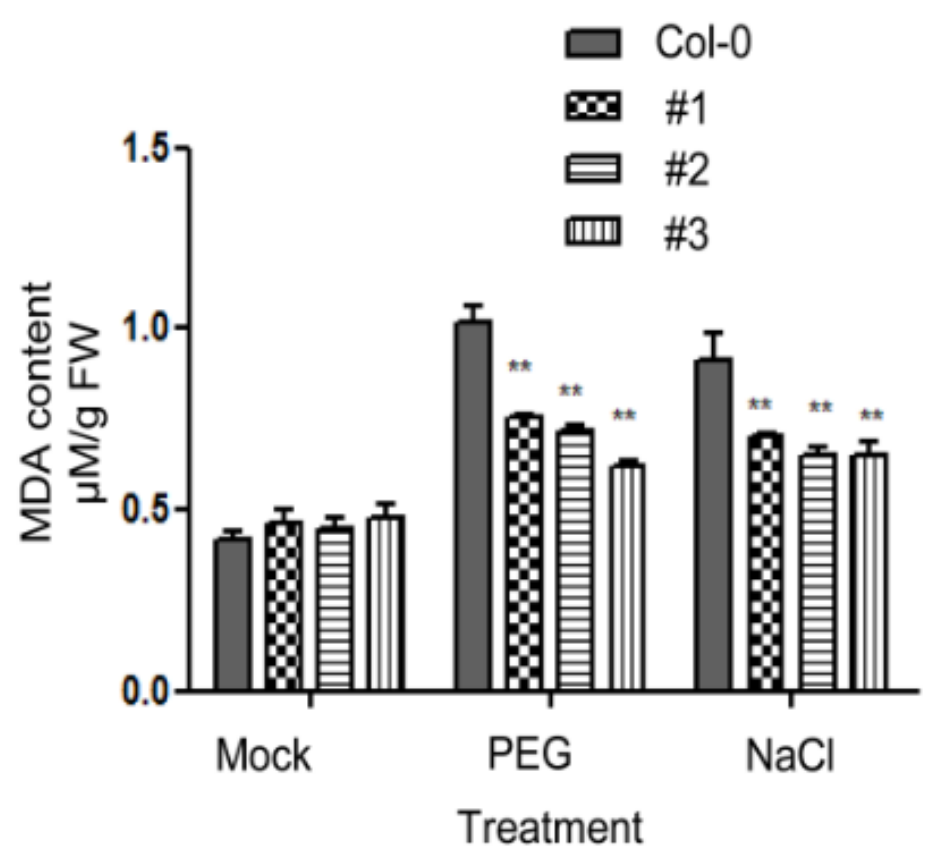

(b)

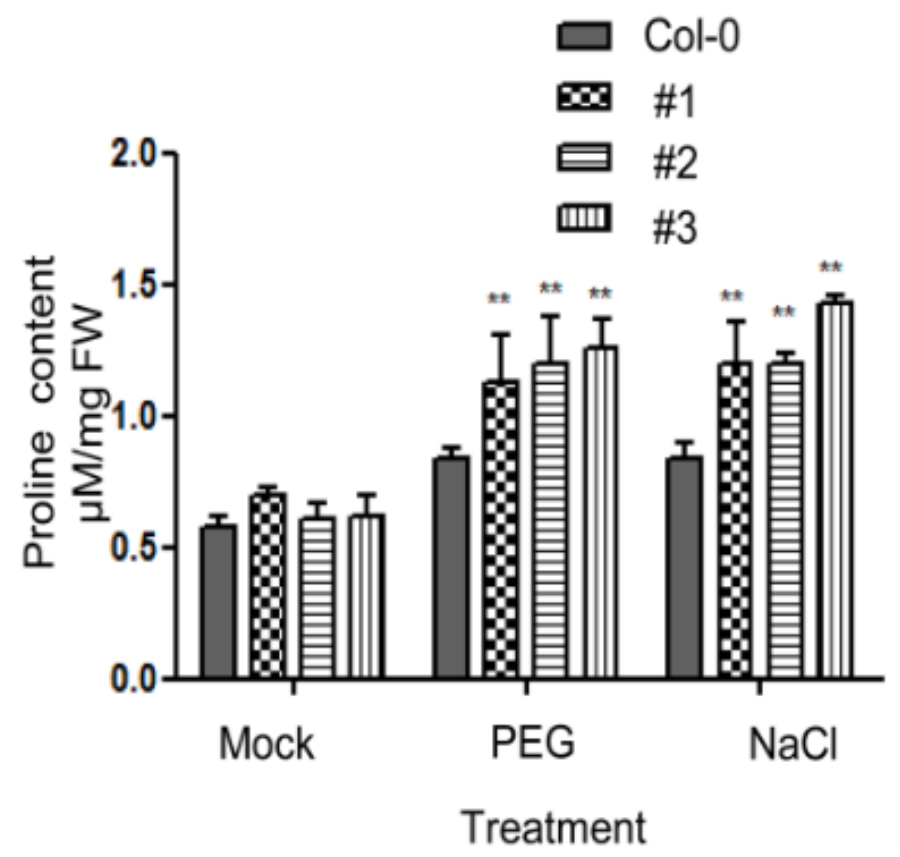

(c)

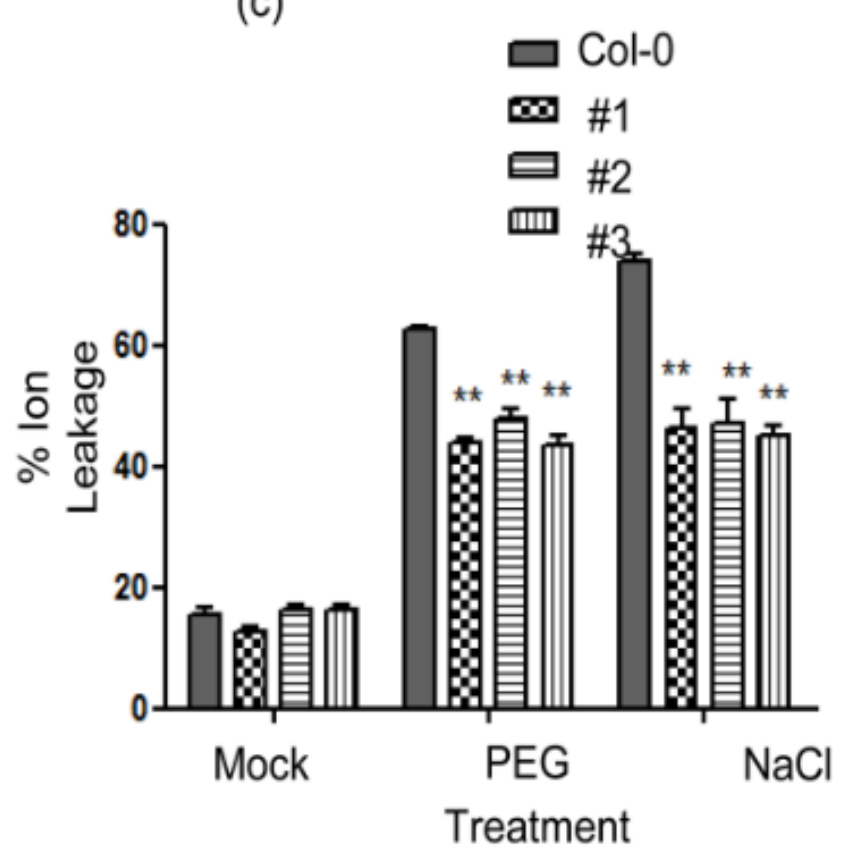

Figure 5

MDA content, proline content and ion leakage under drought (10\% PEG) and salinity (150mM) of EcCAMoverexpression lines and Col-0. A) MDA content comparison. B) Proline content comparison. C) Ion leakage comparison. The data were presented as the mean \pm SD of three independent experiments. Asterisks above each column indicate statistical difference between overexpression lines and Col-0 ( ${ }^{*} \mathrm{P}<$ $\left.0.05 ;{ }^{* *} \mathrm{P}<0.01 ; * * * \mathrm{P}<0.001\right)$ by one-way ANOVA. 


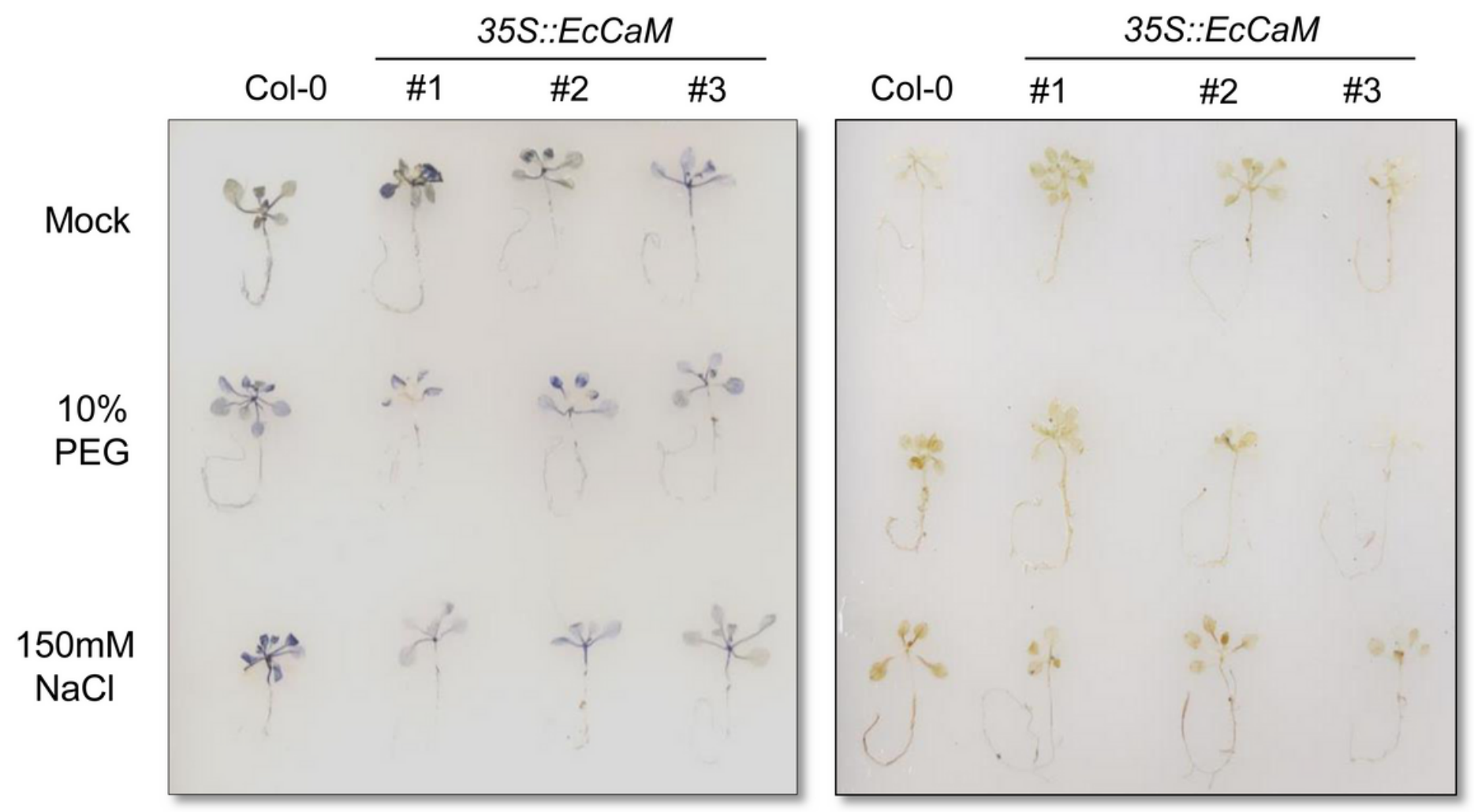

\section{Figure 6}

ROS detection under PEG and $\mathrm{NaCl}$ stress conditions. A) Superoxide (O2-) accumulation detected by NBT staining. B) Peroxide (H2O2) accumulation detected by DAB staining. 
(a)

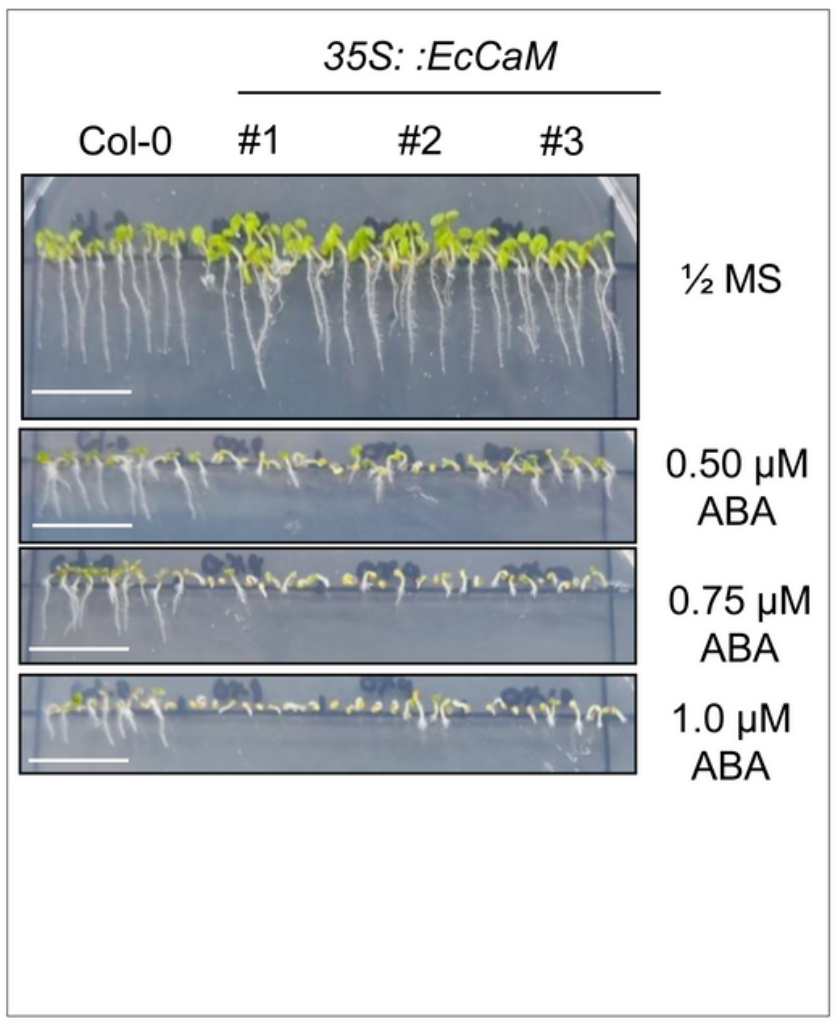

(b)

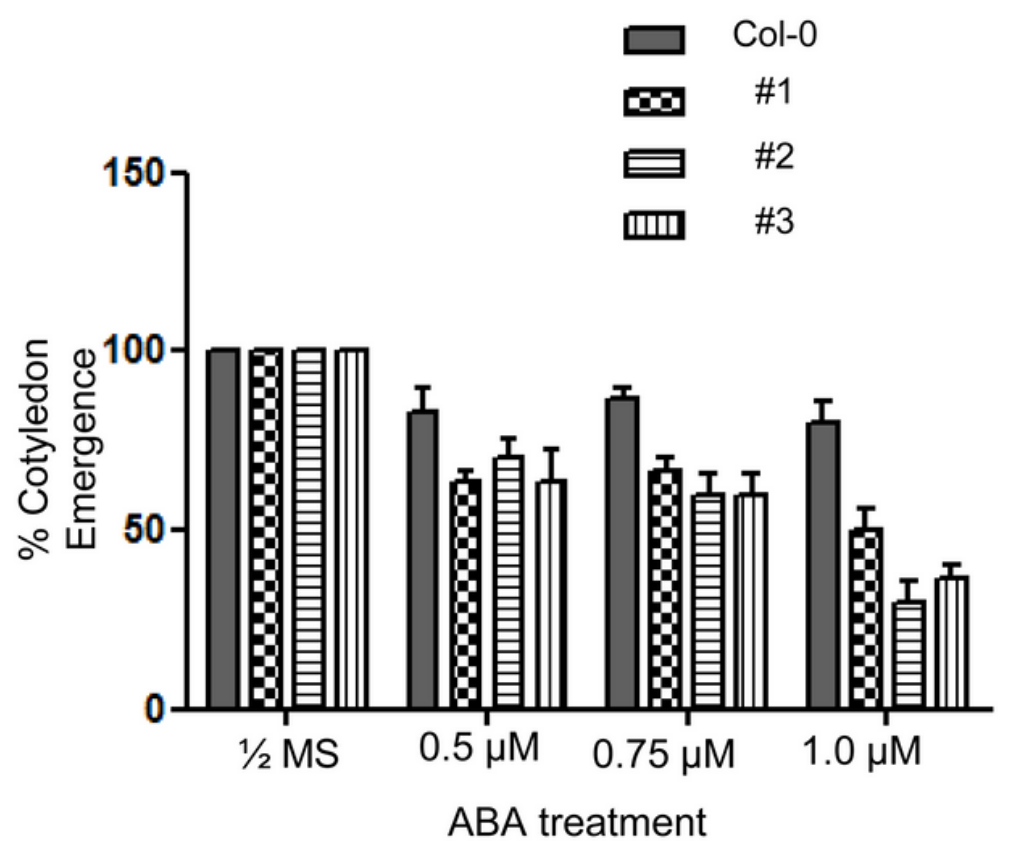

Figure 7

Overexpression of EcCAM in Arabidopsis increased ABA sensitivity. A) EcCAM-overexpression and WTCol- 0 seeds were germinated on $1 / 2$ MS medium supplemented various ABA concentration $(0,0.5,0.75$ and $1 \mu \mathrm{M}$. B) Cotyledon emergence $\%$. 
(a)

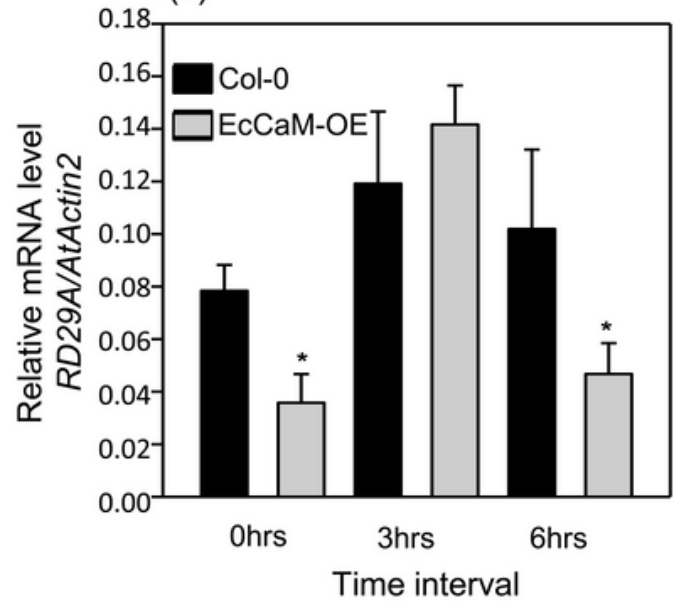

(c)

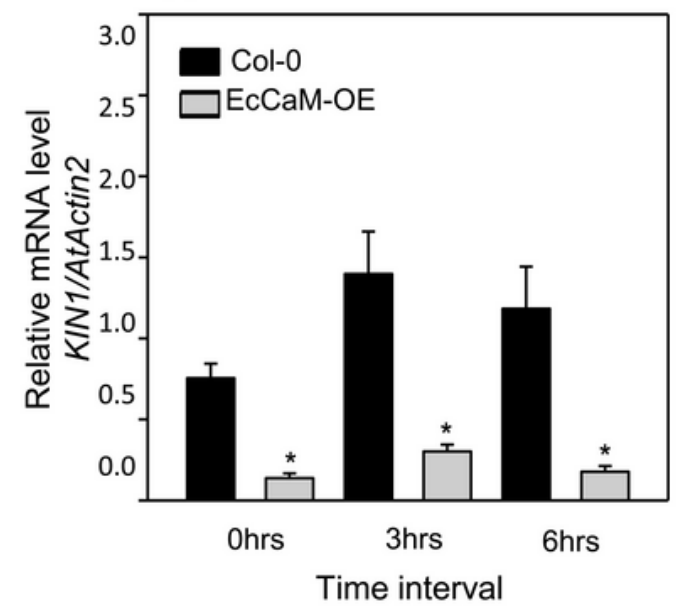

(b)

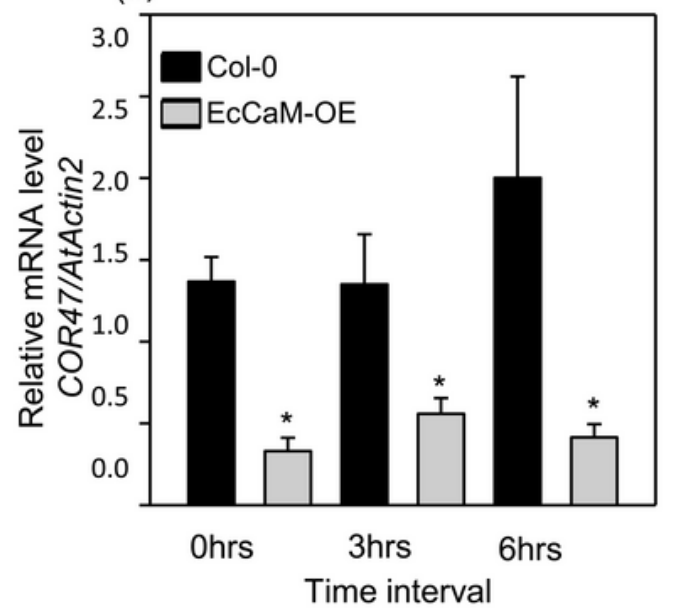

(d)

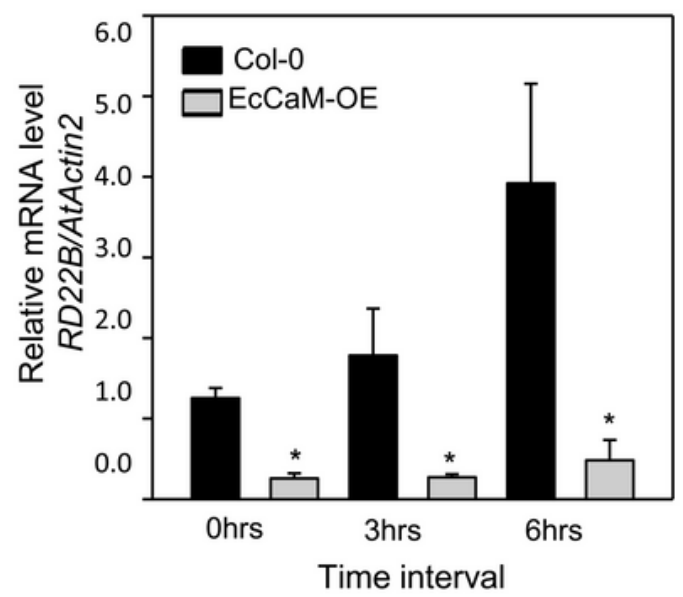

(e)

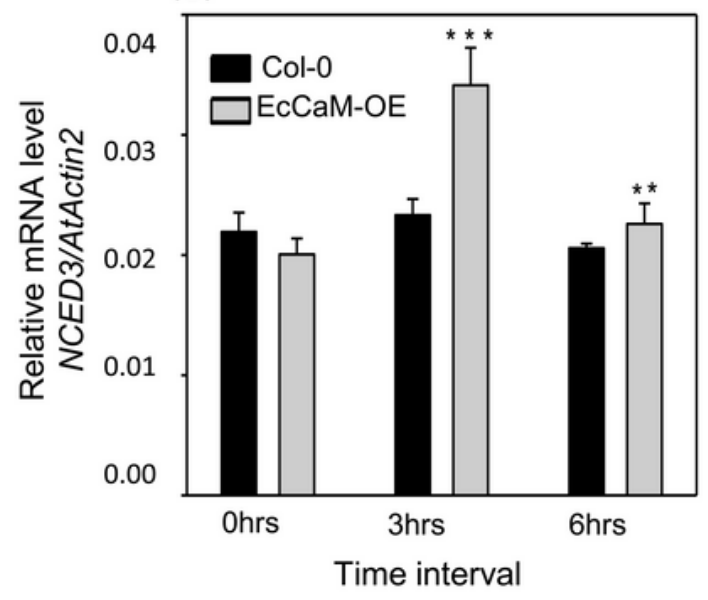

Figure 8

Relative expression profiling of stress-responsive genes under drought stress. A) RD29A B) COR47 C) KIN1 D) RD22 E) NCED3. The data were presented as the mean \pm SD of three independent experiments. Asterisks above each column indicate statistical difference between Col-0 and overexpression lines ( ${ }^{*} \mathrm{P}<$ $0.05 ; * \star \mathrm{P}<0.01 ; * \star \star \mathrm{P}<0.001)$ by one-way ANOVA. 
(a)

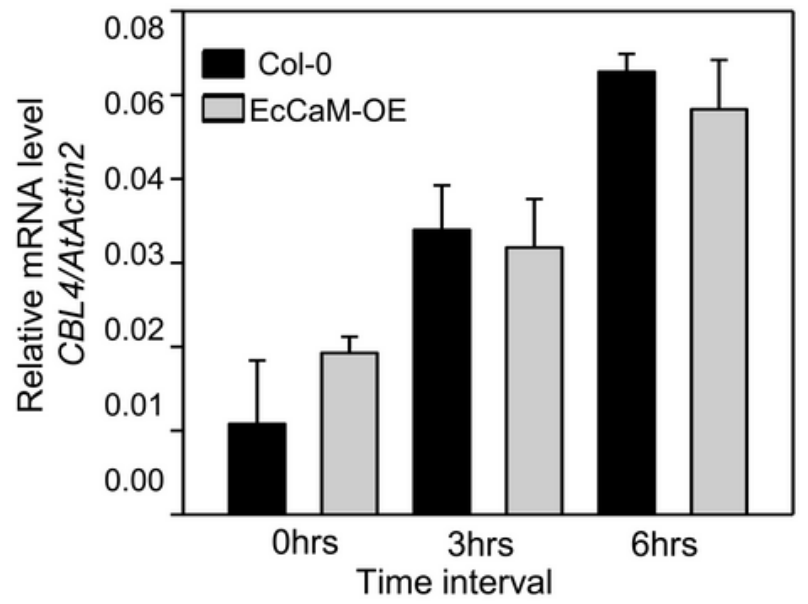

(c)

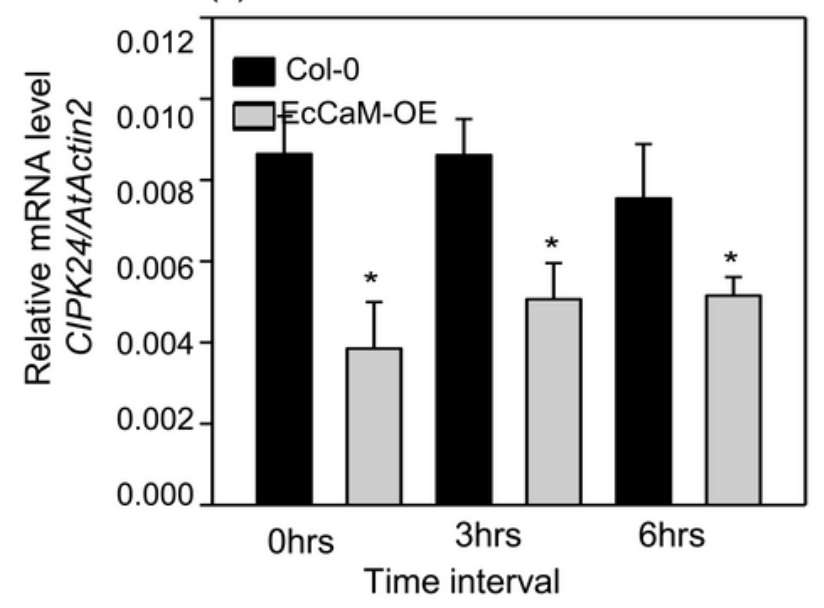

(e)

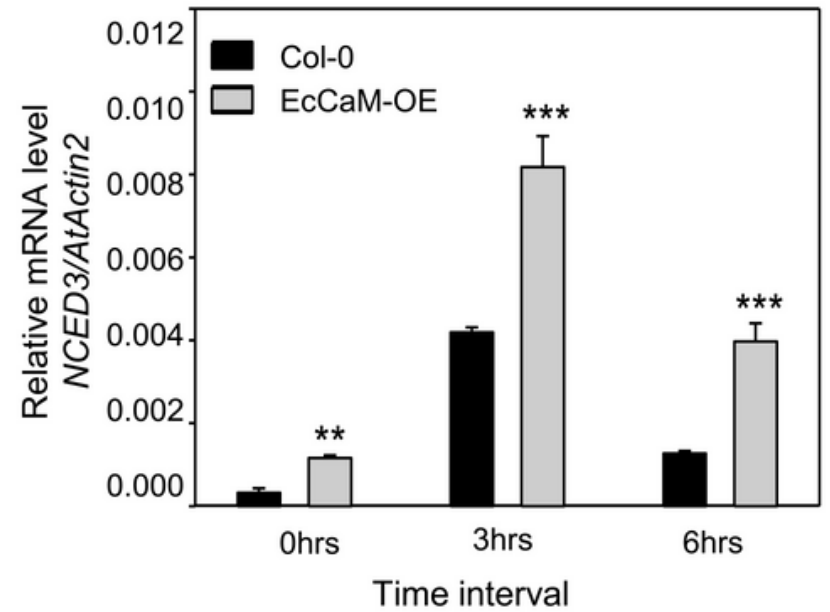

\section{Figure 9}

Relative expression profiling of stress-responsive genes under salt stress. A) CBL4 B) CBL10 C) CIPK24 D) NHX1 E) NCED3. The data were presented as the mean \pm SD of three independent experiments. Asterisks above each column indicate statistical difference between Col-0 and overexpression lines ( ${ }^{*} \mathrm{P}<$ $\left.0.05 ;{ }^{* \star P}<0.01 ; * \star \star P<0.001\right)$ by one-way ANOVA. 